\title{
The Effects of Rhythm and Robotic Interventions on the Imitation/Praxis, Interpersonal Synchrony, and Motor Performance of Children with Autism Spectrum Disorder (ASD): A Pilot Randomized Controlled Trial
}

\author{
Sudha M. Srinivasan, ${ }^{1}$ Maninderjit Kaur, ${ }^{1}$ Isabel K. Park, ${ }^{2}$ Timothy D. Gifford, ${ }^{3}$ \\ Kerry L. Marsh, ${ }^{3}$ and Anjana N. Bhat ${ }^{1,2,3,4}$ \\ ${ }^{1}$ Department of Physical Therapy, Biomechanics and Movement Sciences, University of Delaware, Newark, DE 19713, USA \\ ${ }^{2}$ Physical Therapy Program, Department of Kinesiology, University of Connecticut, Storrs, CT 06269, USA \\ ${ }^{3}$ Center for Health, Intervention, and Prevention, Department of Psychology, University of Connecticut, Storrs, CT 06269, USA \\ ${ }^{4}$ Behavioral Neuroscience Program, Department of Psychology, University of Delaware, Newark, DE 19713, USA \\ Correspondence should be addressed to Anjana N. Bhat; abhat@udel.edu
}

Received 17 July 2015; Revised 6 November 2015; Accepted 26 November 2015

Academic Editor: Klaus-Peter Ossenkopp

Copyright ( $) 2015$ Sudha M. Srinivasan et al. This is an open access article distributed under the Creative Commons Attribution License, which permits unrestricted use, distribution, and reproduction in any medium, provided the original work is properly cited.

\begin{abstract}
We assessed the effects of three interventions, rhythm, robotic, and standard-of-care, on the imitation/praxis, interpersonal synchrony, and overall motor performance of 36 children with Autism Spectrum Disorder (ASD) between 5 and 12 years of age. Children were matched on age, level of functioning, and services received, prior to random assignment to one of the three groups. Training was provided for 8 weeks with 4 sessions provided each week. We assessed generalized changes in motor skills from the pretest to the posttest using a standardized test of motor performance, the Bruininks-Oseretsky Test of Motor Proficiency, 2nd edition (BOT-2). We also assessed training-specific changes in imitation/praxis and interpersonal synchrony during an early and a late session. Consistent with the training activities practiced, the rhythm and robot groups improved on the body coordination composite of the BOT-2, whereas the comparison group improved on the fine manual control composite of the BOT-2. All three groups demonstrated improvements in imitation/praxis. The rhythm and robot groups also showed improved interpersonal synchrony performance from the early to the late session. Overall, socially embedded movement-based contexts are valuable in promoting imitation/praxis, interpersonal synchrony, and motor performance and should be included within the standard-of-care treatment for children with ASD.
\end{abstract}

\section{Introduction}

Children with Autism Spectrum Disorder (ASD) have persistent impairments in social communication skills including impaired initiation of social interactions, poor sharing of interests with social partners, impairments in verbal and nonverbal communication skills as well as repetitive and restricted interests including repetitive actions on objects, circumscribed interests, and stereotyped speech [1-4]. In addition, between 50 and $100 \%$ of individuals with ASD have motor difficulties including incoordination during gross and fine motor activities, poor balance skills, and clumsy gait patterns [5-10]. They also demonstrate impairments in motor imitation, praxis, and interpersonal synchrony [1115]. Motor impairments in infancy and early childhood have implications for future social, cognitive, and communication development in autism [16]. For example, impairments in basic gross motor skills such as running, jumping, and hopping as well as poor interpersonal synchrony can limit children's play with peers and restrict their opportunities to build social connections and friendships $[5,16]$. Similarly, poor manual motor skills such as pointing, requesting, and reaching have implications for nonverbal modes of communication such as use of gestures and engaging in joint 
attention bids [17]. Poor imitation and praxis skills will limit children's opportunities to learn and refine complex motor skills such as bicycling, playing soccer, and so forth through observation of others' actions [5, 9, 18-20]. Overall, there is substantial evidence supporting the far-reaching cascading effects of motor difficulties on the core impairments in autism. Not surprisingly, motor skills of children with ASD at age 2 were predictive of optimal outcomes at age 4 [21]. Given this unequivocal evidence on the impact of motor skills in ASD, there is a need for intensive research dedicated towards understanding and remediating the motor impairments in children with ASD.

Impairments in gross and fine motor performance as well as interpersonal synchrony are evident from an early age in individuals with ASD [14, 22-26]. In terms of gross motor performance, children have significant impairments in postural control [27-30], gait patterns [6, 31, 32], and bilateral coordination skills $[14,26]$. Similarly, children with ASD have impaired fine motor skills involving object control and manual dexterity [33-36], visuomotor integration [9], and handwriting [37-39]. A recent meta-analysis based on 51 studies comparing children with ASD and typically developing (TD) controls demonstrated a large effect size of 1.2 for motor issues in gait, postural control, motor coordination, upper limb control, and motor planning in ASD [10]. Moreover, overall motor performance is associated with the severity of diagnostic symptoms [8, 40], level of adaptive functioning [41], and level of social withdrawal [29] in autism. Children with ASD also have difficulties in interpersonal synchrony [14]. Interpersonal synchrony involves coordinating one's actions with those of social partners and it requires appropriate social attention, imitation, and turn taking skills [13, 26, 4247]. For example, during a rocking chair task that examined spontaneous interpersonal synchrony between the parent and their child, children with autism showed significantly less in-phase rocking coordination compared to TD children [14]. Overall, given the pervasive nature of motor impairments, it is critical that goals related to motor performance and interpersonal synchrony be brought to the forefront during planning and implementation of interventions for children with ASD.

Difficulties in imitation have been documented in toddlers and young children with ASD [11, 48, 49] and are thought to continue into adulthood [11, 12, 50, 51]. Poor imitation skills may be associated with the core social communication, affective, and cognitive impairments in ASD [52, 53]. Two different types of imitative actions have been described in the literature. Based on object use, there are transitive actions or actions on objects (e.g., hammering a nail) and intransitive actions or actions without objects (e.g., clapping hands). Based on purpose, there are meaningful actions (e.g., actions that convey communicative intent such as waving "bye") and nonmeaningful actions (e.g., noncommunicative actions such as placing hand on chest) [54, 55]. Young children with ASD had lower imitation scores compared to TD children and children with developmental delays, with greater difficulties in imitation of intransitive compared to transitive actions [49]. Similarly, children had greater impairments in imitation of meaningless versus meaningful actions and imitation impairments were associated with children's overall motor ability levels [56]. Deficits in imitation have also been hypothesized to be part of a more generalized impairment in praxis $[57,58]$. Praxis is the ability to plan and execute a series of actions/gestures following imitation, on verbal command, and during tool use $[57,58]$. High-functioning children with ASD had impairments in production of gestures on imitation, on verbal command, and during tool use compared to TD children, suggestive of a broader impairment in praxis [58]. Taken together, imitation and praxis impairments are associated with language and play skills as well as levels of symptom severity in children with ASD [40, 49, 59-61]. In spite of considerable evidence on motor impairments, there is little previous research supporting the use of movement-based interventions in ASD. However, recently, there has been growing emphasis on the need for early interventions with a focus on active play and enriched movement experiences to promote multisystem development in ASD $[5,18]$.

Contemporary interventions that target imitation skills include naturalistic and developmental clinician/caregivermediated interventions $[62,63]$, peer-mediated interventions $[64,65]$, and video-modeling interventions [66]. Naturalistic and developmental interventions aim to teach imitation within naturalistic, developmentally appropriate social interactions [62, 63]. A 10-week randomized controlled trial using clinician-delivered Reciprocal Imitation Training (RIT) techniques such as contingent imitation, linguistic mapping, modeling, prompting, and contingent natural reinforcement led to improvements in imitation skills in the treatment group but not in the control group that received treatment as usual [67]. In contrast, peer-mediated training involves adults prompting children with ASD to imitate the behaviors of their TD peers; such training led to improvements in imitation of actions on objects as well as generalization of learned skills to novel actions within novel environments [64]. Lastly, motivating approaches such as video modeling, where children with ASD are asked to watch a video clip of the target behavior and then imitate the modeled behavior, have led to better learning of skills such as toy play, brushing, and greeting compared to live modeling techniques [66]. Although several contemporary autism interventions target social imitation, there is currently a lack of evidence on interventions targeting gross/fine motor performance and interpersonal synchrony. In the current study, we explored the effects of two 8-week novel, movement-based rhythm and robotic interventions on the overall motor performance, imitation/praxis, and interpersonal synchrony skills of children with ASD.

Recently, novel intervention approaches such as rhythm and robotic therapies have been used to promote social communication skills in children with ASD [68-70]. Children with autism have a predisposition for musical stimuli, find musical experiences very enjoyable, and have intact musical perception in spite of significant impairments in language skills $[68,71,72]$. Therefore, rhythm-based contexts have been used to enhance verbal and nonverbal communication as well as behavioral skills in ASD $[68,69,73,74]$. For example, a meta-analysis based on 10 studies and 165 individuals with 
ASD showed improvements in primary core symptoms of autism including social interaction, verbal communication, initiation of behavior, and social-emotional reciprocity as well as secondary outcomes including social adaptation skills and quality of parent-child relationships [73]. Despite considerable evidence on positive effects of rhythmic interventions on core social communication symptoms, interestingly, few studies have used such contexts to facilitate motor skills in children with ASD $[75,76]$. For example, a musical social routine focusing on reciprocal imitation between the child and the experimenter led to improved spontaneous word and action imitation in 3 out of 4 children with ASD, with carryover effects observed in 2 children [75]. In contrast to the limited literature in autism, there is considerable evidence that rhythmic accompaniment using music can promote gross and fine motor skills in TD children [77-81]. A 10week music and movement program in preschoolers led to greater improvements in locomotor skills assessed on the standardized, Test of Gross Motor Development (TGMD), compared to a control group that engaged in free play [79]. Overall, music-based contexts seem to be a promising tool to facilitate motor skills in children with ASD [74]. In the current study, we systematically examined the effects of a prolonged rhythm intervention on the motor skills of children with ASD using a randomized controlled trial (RCT) design.

Robotic interactions are highly motivating environments for children with ASD due to the simple, predictable, and nonintimidating nature of robots compared to humans [82, 83]. Children can use robots as a "social crutch" to practice turn taking, language, and joint attention skills; it is hypothesized that they would eventually transfer learned skills to interactions with humans [70, 82, 84]. Robot-child interactions have also been used to encourage imitation skills within structured as well as free play environments [83, 85-90]. For example, following 7 weeks of structured training, low-functioning children paired with a robot mediator demonstrated greater shared attention and imitation of facial expressions of the robot compared to children paired with the human mediator [85]. In spite of these promising results, none of the aforementioned studies systematically assessed changes in imitation or praxis performance following training. Furthermore, studies did not use standardized tests to assess changes in overall motor performance following robotic interactions. Our own previous work suggests objective improvements in imitation/praxis and bilateral coordination following a 4-week robot-adultchild intervention protocol using a 7-inch humanoid robot, Isobot (Tony, Inc.) in $15 \mathrm{TD}$ children and 1 child with autism [91-93]. In the present study, we address limitations in the current literature by extending our work to a larger sample of children with ASD and systematically examining the effects of a prolonged robotic intervention using a humanoid robot, Nao, on training-specific measures of imitation/praxis and interpersonal synchrony assessed within the training context, as well as overall motor performance assessed on a standardized test outside the training context.

Taken together, in spite of the growing recognition of motor impairments in ASD, there is currently little evidence on comprehensive intervention programs that target gross and fine motor performance in autism. Moreover, evidence on novel rhythm and robotic therapies is anecdotal and limited in its application due to small sample sizes, limited training durations, lack of use of standardized assessments, and detailed coding schemes, as well as lack of methodological rigor and experimental controls. The current RCT aimed to address these gaps by comparing the effects of prolonged 8 -week rhythm and robotic interventions to those of a standard-of-care comparison intervention on the motor skills of children with ASD. Note that we are currently reporting effects of these interventions on the social communication and behavioral skills through other publications. All three groups engaged in imitation-based activities within group contexts. The movement groups engaged in whole-body gross motor and fine motor imitation games to the beat of music whereas the comparison group engaged in sedentary tabletop fine motor imitation activities. We assessed changes in generalized motor performance from pretest to posttest using a standardized test of motor performance, namely, the Bruininks-Oseretsky Test of Motor Proficiency, 2nd edition (BOT-2) [93]. We also assessed changes in training-specific measures of imitation/praxis and interpersonal synchrony from an early to a late training session. We hypothesized that consistent with the training demands, the movement groups would show improvements in gross motor performance (balance and bilateral coordination subtests), whereas the comparison group would demonstrate improvements in fine motor performance (fine motor precision and fine motor integration subtests) on the BOT-2. Due to the strong focus on imitation-based games in all groups, we hypothesized that all groups would demonstrate improvements in trainingspecific measures of imitation/praxis. Given the nature of the training activities, we assessed interpersonal synchrony only in the rhythm and robot groups and hypothesized that both groups would demonstrate improvements in synchrony with training.

\section{Method}

2.1. Participants. We recruited 36 children $(32 \mathrm{M}$ and $4 \mathrm{~F}$, 20 Caucasian, 6 African American, 4 Asian, 3 Hispanic, and 3 of mixed ethnicity) between 5 and 12 years of age $(\mathrm{M}(\mathrm{SD})=7.63$ (2.24)) (see Table 1(a) for demographic details) (see Figure 1 for enrollment and allocation details). Children were recruited through fliers posted online and onsite in local schools, services, and self/parent advocacy groups. The Social Communication Questionnaire (SCQ) [94] was used as a screener prior to enrollment. Eligibility was confirmed using the gold standard diagnostic assessment, the Autism Diagnostic Observation Schedule, 2nd edition (ADOS-2) [95], and clinician judgment during a clinical psychology evaluation. Children with significant behavioral impairments or severe receptive language impairments that limited comprehension of 2-step simple instructions were excluded (see Figure 1). All children were enrolled following written parental consent as approved by the Institutional Review Board at the University of Connecticut. All participating families belonged to the upper-middle to upper 
TABLE 1: (a) Demographic characteristics of children in the rhythm, robot, and comparison groups. (b) Baseline motor performance, adaptive behavior, and autism severity of children in rhythm, robot, and comparison groups.

(a)

\begin{tabular}{|c|c|c|c|c|c|}
\hline Participant characteristics & Rhythm group M (SD) & Robot group M (SD) & Comparison group M (SD) & $F$ or $\chi^{2}$ value & $p$ value \\
\hline Age & $7.88(2.56)$ & $7.52(2.22)$ & $7.36(2.02)$ & 0.44 & 0.65 \\
\hline Gender & $10 \mathrm{M}, 2 \mathrm{~F}$ & $11 \mathrm{M}, 1 \mathrm{~F}$ & $11 \mathrm{M}, 1 \mathrm{~F}$ & 0.56 & 0.76 \\
\hline Socioeconomic status & $47.33(10.86)$ & $47.75(8.75)$ & $52.46(10.37)$ & 0.97 & 0.39 \\
\hline
\end{tabular}

(b)

\begin{tabular}{|c|c|c|c|c|c|}
\hline Participant characteristics & $\begin{array}{l}\text { Rhythm group } \\
\mathrm{M}(\mathrm{SD}) \text { and } \\
\text { range }\end{array}$ & $\begin{array}{l}\text { Robot group } M \\
(\mathrm{SD}) \text { and range }\end{array}$ & $\begin{array}{l}\text { Comparison Group } \\
\text { M (SD) and Range }\end{array}$ & $F$ value & $p$ value \\
\hline $\begin{array}{l}\text { Adaptive behavior composite on } \\
\text { the VABS }\end{array}$ & $\begin{array}{l}71.45(11.75) \\
35 \text { to } 94\end{array}$ & $\begin{array}{l}67.91(15.01) \\
41 \text { to } 88\end{array}$ & $\begin{array}{l}75.92(18.43) \\
39 \text { to } 100\end{array}$ & 0.80 & $p$ values $>0.5$ \\
\hline
\end{tabular}

Percentage of children with

$\begin{array}{llll}\text { scores lower than } 1 \text { SD below the } & 81.82 & 90.91 & 66.67\end{array}$

mean

\begin{tabular}{|c|c|c|c|c|c|}
\hline $\begin{array}{l}\text { Total motor scores on the } \\
\text { MABC-2 checklist }\end{array}$ & $\begin{array}{c}30.92(16.40) \\
7 \text { to } 62 \\
\end{array}$ & $\begin{array}{l}37.5(13.06) \\
3 \text { to } 50 \\
\end{array}$ & $\begin{array}{c}30.5(14.50) \\
8 \text { to } 50 \\
\end{array}$ & 1.45 & $p$ values $>0.3$ \\
\hline $\begin{array}{l}\text { Percentage of children below } \\
\text { age-based cut-off scores }\end{array}$ & 75 & 83.33 & 66.67 & & \\
\hline ADOS-2 comparison score & $\begin{array}{c}8.5(1.24) \\
6 \text { to } 10\end{array}$ & $\begin{array}{c}7.92(1.78) \\
5 \text { to } 10\end{array}$ & $\begin{array}{c}8.42(1.72) \\
5 \text { to } 10\end{array}$ & 0.46 & $p$ values $>0.3$ \\
\hline
\end{tabular}

Note. On the VABS, higher scores indicate better functioning; on the MABC-2 caregiver checklist, higher scores indicate poor motor performance; on the ADOS-2, and higher comparison scores indicate high autism severity.

class in terms of their socioeconomic status $(\mathrm{M}(\mathrm{SD})=$ 49.18 (10.03)) [96] (see Table 1(a)).

Following enrollment, children were matched on age (4$5,6-7,8-9$, and 10-12 years), level of functioning, and amount of prior services and then randomly assigned to one of three groups, rhythm, robot, or comparison using the random number generator in MS Excel (see Table 1(a)). We assessed autism severity using the comparison scores on the ADOS2. The comparison score is a continuous metric ranging from 1 to 10 that describes the severity of a child's autism symptoms compared to children with ASD of similar age and language levels [95]. Low comparison scores are indicative of minimal to no evidence of autism symptoms whereas high scores are indicative of severe autism symptoms. All participating children showed moderate to severe symptoms of ASD and there were no group differences in terms of levels of autism severity ( $p$ values $>0.3$, see Table 1(b)). We assessed children's level of adaptive functioning using the Vineland Adaptive Behavior Scales (VABS) parent questionnaire [97] (see Table 1(b)). Overall, $82 \%$ of our participants had significant delays ( $>1$ SD below the mean) on the Adaptive Behavior Composite; specifically, $70 \%$ children had communication delays, $80 \%$ had delays in daily living skills, and $82 \%$ had delays on the socialization domain with no group differences ( $p$ values $>0.5$ ). We used the caregiver checklist of the Movement Assessment Battery for Children, 2nd edition (MABC-2), to assess motor competence of children between 5 and 12 years of age on a variety of fine and gross motor activities [98] (see Table 1(b)). Overall, 75\% of children in the study had MABC scores below the 15th percentile on the MABC-2 checklist with no group differences ( $p$ values $>0.3$ ).
2.2. Study Characteristics. Our pilot randomized controlled trial lasted for 10 weeks with the pretest and posttest sessions conducted during the first and last weeks of the study, respectively. The training sessions were provided during the intermediate 8 weeks of the study. Children in all three groups, rhythm, robotic, and comparison, were provided a total of 32 sessions (16 expert and 16 parent sessions). Children were provided 2 expert sessions per week with each session lasting for around 45 minutes. In addition, we provided caregivers with detailed instruction manuals, session supplies, and in-person training to practice similar activities during 2 additional home sessions each week. Out of the 32 sessions, all families completed more than $50 \%$ of the sessions (Rhythm: $\mathrm{M}(\mathrm{SD})=73.18$ (19.74), Robot: $\mathrm{M}(\mathrm{SD})=76.82$ (16.72), Comparison: $\mathrm{M}(\mathrm{SD})=$ 80.21 (15.27), $p$ values $>0.05)$.

2.3. Training Protocol. In all three groups, children engaged in training activities within a triadic context involving the child, an expert trainer, and an adult model (see Figures 2(a), 2(b), and 2(c)). The expert trainer was the instructor and guided the child through the activities of the session. In the robot group, the robot was the instructor and the human trainer controlled the robot using a laptop. The adult model served as a buddy and a visual model for the child and provided hand-on-hand assistance, if needed, during the session. The rhythm and robot groups engaged in socially embedded whole-body movement games (see Figures 2(a) and 2(b)), whereas the comparison group engaged in tabletop activities promoting fine motor, social communication, and academic skills within a group setting (see Figure 2(c)). 


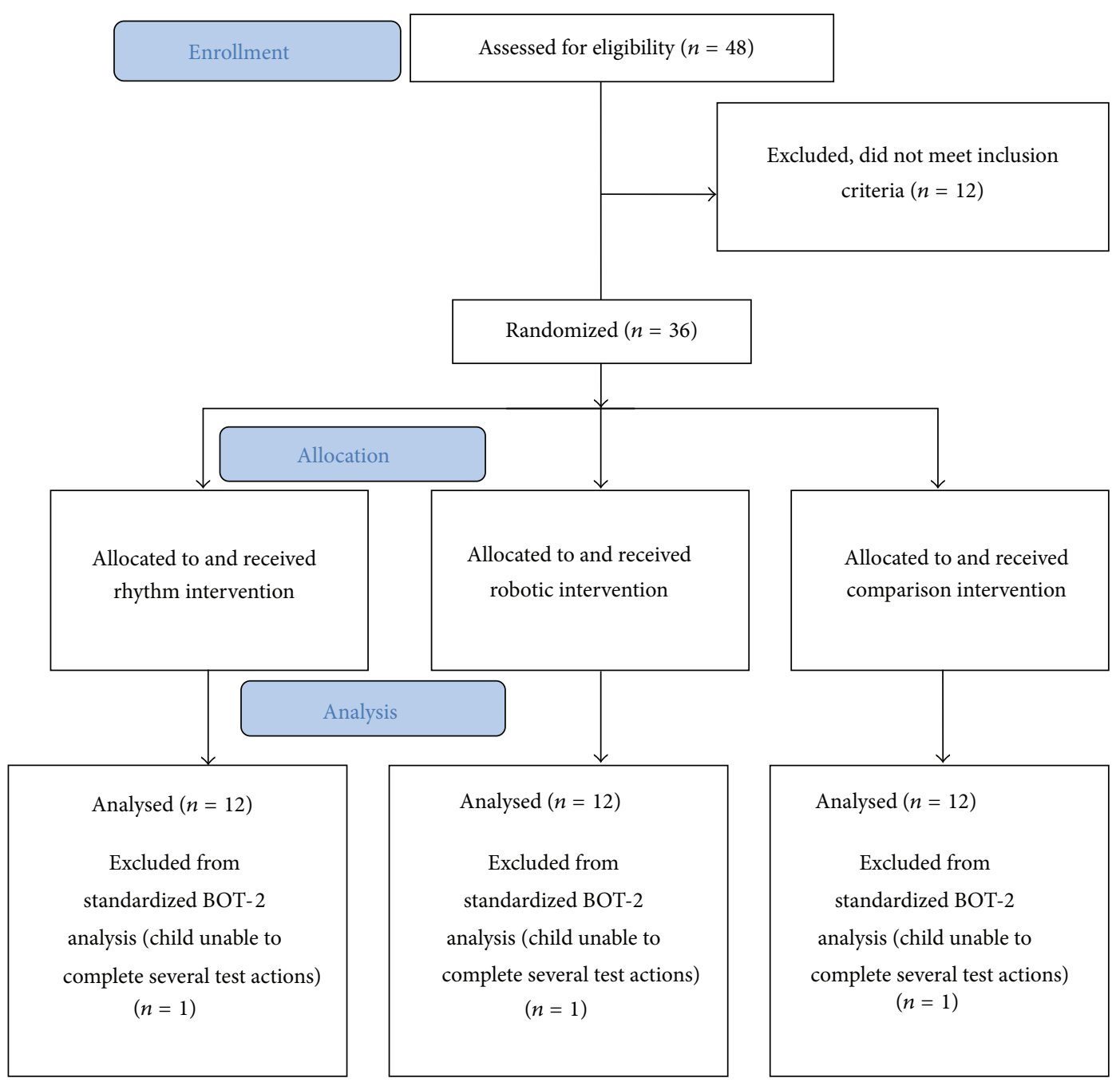

Figure 1: CONSORT flow diagram.

The comparison group was structured to mimic the types of activities that children with autism typically receive in special education settings. In all three groups, we promoted social communication skills such as eye contact, turn taking, greeting/farewell, responding to questions, commenting, asking for help, and use of gestures. In addition, the rhythm and robot groups promoted gross motor skills including balance, bilateral coordination, imitation, interpersonal synchrony, and manual dexterity during joint action games, whereas the comparison group promoted fine motor skills such as symmetrical and asymmetrical grips and pinches, coloring, drawing, cutting, and gluing. All training sessions were videotaped for further behavioral coding.

In all groups, we used training principles derived from current mainstream autism interventions including Applied Behavioral Analysis (ABA) [99], Teaching and Education of Autistic and Related Communication Handicapped Children (TEACCH) [100], and Picture Exchange Communication System (PECS) [101]. For example, we used strategies such as repetition, graded prompting, ensuring structure and consistency in the environment and the individuals involved in the training, and the use of pictures to facilitate transitions. All trainers involved in the study were pediatric physical therapists or physical therapy/kinesiology graduate students who received intensive training from the last author, a music educator, and ABA experts prior to the training sessions. Similarly, all models involved in the study were undergraduate students experienced in working with children with special needs and they received significant training from the last author prior to participation. To assess treatment fidelity, a naïve coder randomly chose and coded one early (sessions 1-5), mid (sessions 6-11), and late (sessions 12-16) session for each child using a comprehensive checklist developed to assess trainer and model behaviors (see Table 4). The coder evaluated (1) accurate completion of critical components of training activities (maximum score $=74$ points), (2) trainer and model behaviors including instructions, prompts, and trainer/model affect (scored on a scale of 1 to 5 with 1 indicating poor quality and 5 indicating highest quality), and (3) child's compliance (scored on a scale of 1 to 5 with 1 indicating poor interest and 5 indicating maximum interest). Overall, across groups, training activities were completed 


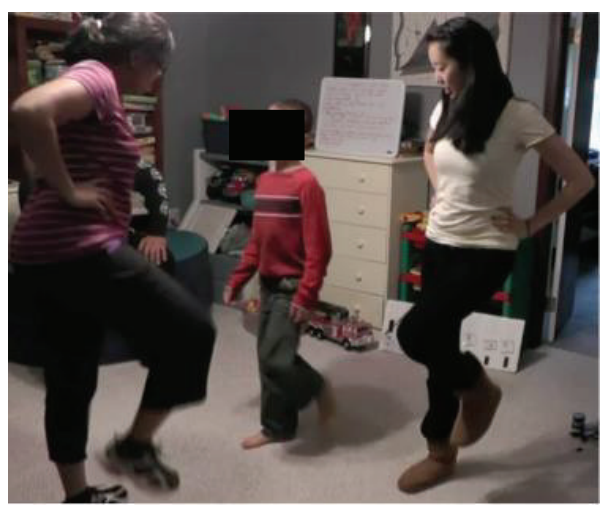

(a)

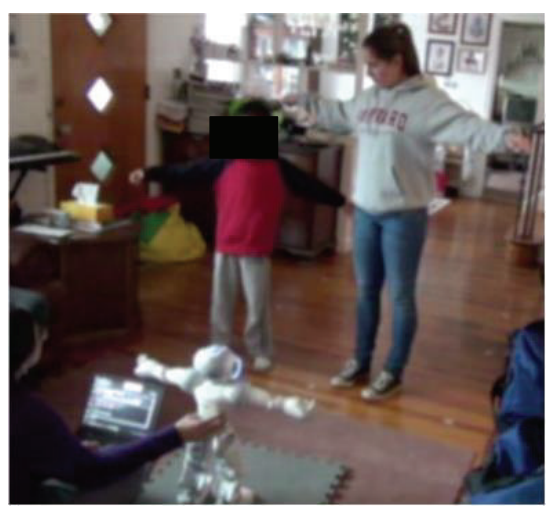

(b)

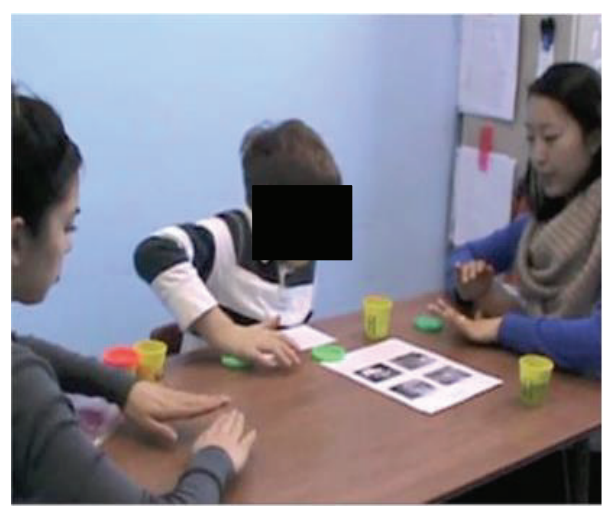

(c)

FIGURE 2: (a) Experimental set-up for a rhythm group training session. (b) Experimental set-up for a robot group training session. (c) Experimental set-up for a comparison group training session.

accurately across sessions (Rhythm: 92.16\% (8.32), Robot: 90.73\% (17.7), Comparison: $91.51 \%$ (5.67)), trainers and models demonstrated greater than optimal adherence to the training protocol (Rhythm: 4.68 (0.39), Robot: 4.36 (0.34), Comparison: $4.65(0.27)$ ), and children showed moderate to high levels of compliance with training (Rhythm: 3.27 (1.14), Robot: 2.67 (0.79), Comparison: 3.95 (0.81)). Next, we describe training activities in each group.

In the rhythm group, children engaged in simple and complex whole-body discrete imitation and interpersonal synchrony-based rhythmic joint action games set to music with the expert trainer and the adult model. Specifically, children engaged in the following movement-based games: action songs that involved finger play, beat keeping routines involving synchronous whole body movements with the adults, improvisational music making that involved synchronous playing of musical instruments, and moving games involving synchronous, locomotor actions such as skipping and jumping (see Table 5).

In the robot group, children engaged with a 23-inch humanoid robot, Nao, and a mobile robot, Rovio, during a variety of dual and multilimb imitation and synchronybased games. Children practiced the following movementbased activities in each session: warm-up game involving body stretches, action game involving upper and lower body synchrony games, drumming game involving practice of simple and complex drumming patterns, and walking game involving tracing letters and shapes on the floor while following the Rovio robot (see Table 5).

In the comparison group, children engaged in several tabletop activities that promoted academic and fine motor skills. Children engaged in reading developmentally appropriate books, building games that involved making creations using supplies such as Play-Doh, Duplos/Legos, and Zoob (Infinitoy), and art-craft activities involving drawing, cutting, coloring, gluing, and pasting to build theme-based creations. We encouraged fine motor skills including symmetrical and asymmetrical hand movements such as rolling, pressing, pulling apart, pushing together, and different types of grips and pinches, as children engaged in imitation games involving building supplies (see Table 5).

2.4. Testing Protocol. We assessed generalized changes in gross and fine motor performance using the standardized test, Bruininks-Oseretsky Test of Motor Proficiency, 2nd edition (BOT-2) [93]. In addition, we assessed training-specific changes in imitation/praxis and interpersonal synchrony by coding custom-developed test activities in the early and late part of the intervention. 
2.4.1. Standardized Test of Motor Performance. The BOT-2 is a reliable and valid assessment of gross and fine motor performance for individuals between 4 and 21 years of age [93]. We assessed changes in motor performance using the fine motor precision (FMP), fine motor integration (FMI), bilateral coordination (BC), and balance (BA) subtests of the BOT-2. The FMP subtest consists of 7 activities that assess precise hand and finger control, the FMI subtest includes 8 items that assess the ability to reproduce drawings of geometric shapes, the BC subtest consists of 8 items that assess the ability to sequentially and simultaneously synchronize upper and lower limbs, and the BA subtest consists of 9 items that evaluate postural control skills during standing and walking. We used the standard scores on the body coordination composite and fine manual control composite to assess for training-related changes in motor performance. The body coordination composite is based on the on the $\mathrm{BC}$ and BA subtests and the fine manual control composite is based on the FMP and FMI subtests of the BOT-2. A novel tester blinded to the grouping of the child conducted the BOT-2 assessment during the pretest and posttest sessions. The first and the third author coded the entire dataset after establishing inter- and intrarater reliability of greater than $85 \%$ using $20 \%$ of the dataset. The dependent variable was the standard scores on the body coordination and fine manual control composites of the BOT- 2 in the pretest and posttest sessions.

2.4.2. Training-Specific Test of Imitation/Praxis. We developed a set of test actions that were representative of the training activities practiced in each group and administered these activities during an early and late training session. Imitation was assessed during the action song and xylophone games in the rhythm group, during the action and drumming games in the robot group, and during building games using PlayDoh, Duplo/Lego blocks, and Zoob (Infinitoy) pieces in the comparison group (see Table 2 for details). Using video data from the training session, we coded imitation accuracy of children during test actions by assessing errors in spatial and temporal aspects of movement execution relative to actions of the trainer. This coding scheme was developed using the error classification reported in the praxis literature [102] (see Table 3 for details). A score of 0 indicated no error and a score of 1 indicated an error within the specific error category. We also recorded the types of prompts, visual, verbal, or manual hand-on-hand assistance, that children required to complete the actions. The total imitation error score was calculated as the sum of error scores on all individual error categories during the test actions. A single coder coded the entire dataset after establishing inter- and intrarater reliability of over $90 \%$ using $20 \%$ of the dataset. Our dependent variable was the percent total imitation error during test actions administered in the early and late training sessions in each group.

2.4.3. Training-Specific Test of Interpersonal Synchrony. We assessed changes in interpersonal synchrony between children and their adult partners in the rhythm and robot groups during an early and late training session. Interpersonal synchrony was assessed during the beat keeping, music making, and moving game activities in the rhythm group and during the action, drumming, and walking game activities in the robot group (see Table 2 for details). The comparison group was excluded from this analysis, since they did not engage in whole-body rhythmic actions promoting interpersonal synchrony. In the rhythm and robot groups, we assessed for the percent duration of time that children were insynchrony (movements synchronized in time and spatially in the same or opposite direction as the adult), out-of-synchrony (movements not synchronized in time and space with the adult), and in assisted-synchrony (manual assistance provided to synchronize movements with the adult) relative to the adult. A single coder coded all the data using Openshapa video coding software after establishing inter- and intrarater reliability of $>84 \%$ using $20 \%$ of the dataset.

2.5. Statistical Analysis. We checked our data for assumptions of normality and homogeneity of variances. The data from the standardized BOT-2 test satisfied all assumptions of parametric statistics. We used repeated measures ANCOVA with composite type (body coordination and fine manual control) and test session (pretest and posttest) as withinsubjects factors and group as the between-subjects factor. In addition, to control for the effect of autism severity on motor performance, we added the ADOS-2 comparison scores as a covariate in the analysis. Data from our training-specific measure of imitation/praxis and interpersonal synchrony were not normally distributed. Hence, we conducted a square root transformation and used transformed data in our analyses. Moreover, since the tests employed to assess imitation/praxis and synchrony were different in the three groups, we conducted separate analyses for each group. We used dependent $t$-tests to assess changes in imitation/praxis from the early to the late session within each group. For assessing changes in interpersonal synchrony, we conducted separate repeated measures ANOVAs for the rhythm and robot groups with session (early, late) and synchrony type (in-synchrony, out-of-synchrony, assisted-synchrony) as the within-subjects factors. For the ANOVAs, in case of main and interaction effects involving the same factor, we assessed the interaction effects only. In case of violations of the assumption of sphericity, Greenhouse Geisser corrections were applied. Post hoc testing was done using dependent $t$-tests. We report effect sizes using partial eta-squared $\left(\eta_{p}{ }^{2}\right)$ and standardized mean difference (SMD) [103] values. Statistical significance was set at $p \leq 0.05$.

\section{Results}

3.1. Standardized Test of Motor Performance. For this analysis, we excluded 3 out of the 36 children since they were low functioning and could not perform a majority of the test actions of the BOT-2, in both the pretest and posttest sessions. The final analysis was therefore based on 11 children per group. The repeated measures ANCOVA indicated significant interaction effect of test session $x$ composite type $x$ group $\left(F(2,29)=3.44, p=0.05, \eta_{p}^{2}=0.19\right)$. We report post hoc analysis of the significant interaction as between-group differences and within-group changes. 


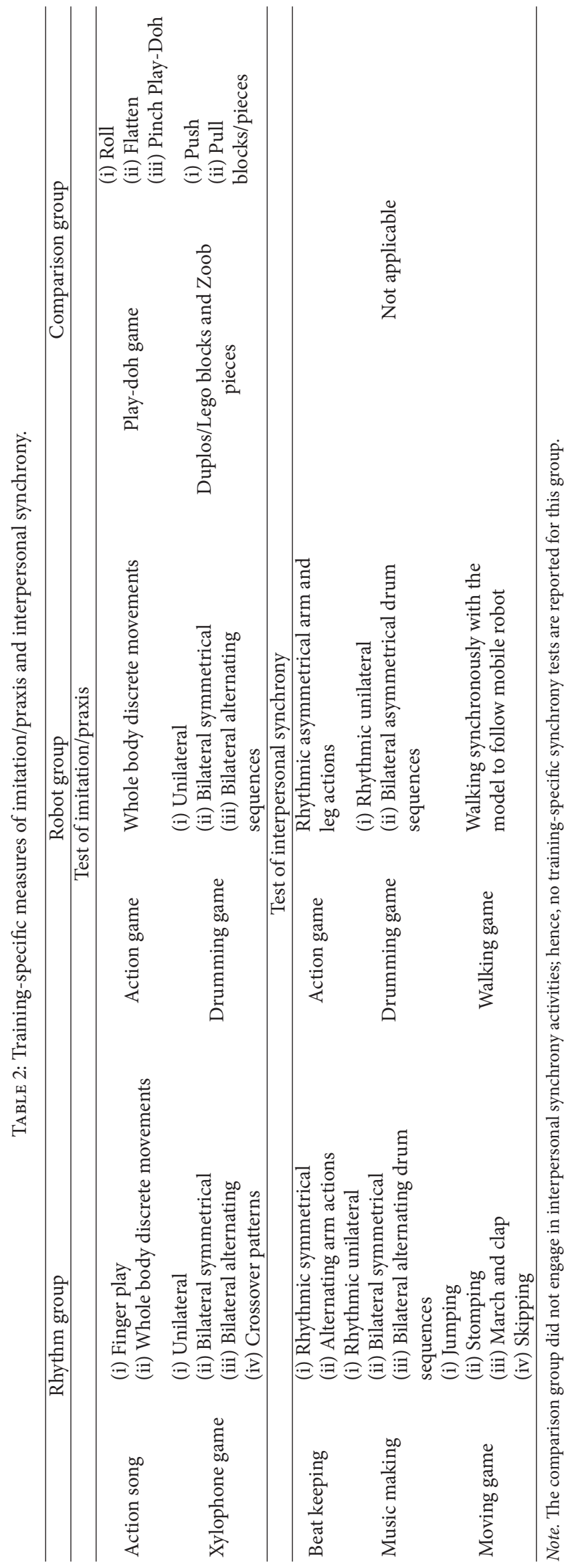


TABLE 3: Coding scheme to assess imitation/praxis errors.

\begin{tabular}{ll}
\hline Imitation errors & Definitions \\
\hline Spatial & Incorrect positioning and orientation of joints involved \\
\hline Body part & Use of incorrect body parts \\
\hline Movement modulation & $\begin{array}{l}\text { Movements are either insufficient or exaggerated in terms of effort and range of motion compared } \\
\text { to the trainer }\end{array}$ \\
\hline Movement precision & $\begin{array}{l}\text { Incorrect sequence of movements within a pattern including omission of steps or addition of } \\
\text { extra steps }\end{array}$ \\
\hline Pace & Movements slower or faster than the trainer \\
\hline Symmetry/reciprocity & Two sides of the body are used incorrectly or immaturely to perform test actions \\
\hline Mirroring & Child failed to mirror actions of the trainer \\
\hline
\end{tabular}

TABLE 4: A checklist to assess fidelity of the training sessions.

\begin{tabular}{|c|c|}
\hline Checklist criteria & Exemplar behaviors assessed \\
\hline Eye contact & Trainer and model elicit eye contact from child during social interactions \\
\hline Ready response & Trainer asks child if he/she is ready before each activity \\
\hline Use of PECS board & Trainer takes child through the activities of the day using the PECS board \\
\hline Session theme & $\begin{array}{l}\text { Trainer explains the theme of the session to the child } \\
\text { Example: "Today's theme is turn taking. When I move you watch, and when I stop it is your turn to } \\
\text { move" }\end{array}$ \\
\hline Activity introduction using PECS & $\begin{array}{l}\text { Trainer introduces activity using picture boards } \\
\text { Example: "Let's get ready for music making" while pointing at the picture for "music making" }\end{array}$ \\
\hline Help with setup & $\begin{array}{l}\text { Trainer and model ask child to help with setup for each activity. } \\
\text { Example: "Can you pass that blue Lego block to me..." }\end{array}$ \\
\hline Presentation of activity & $\begin{array}{l}\text { At the beginning of each activity, trainer gives simple instructions for the activity } \\
\text { Example: "Now, we will copy the robot" }\end{array}$ \\
\hline Activity-specific bids & $\begin{array}{l}\text { Appropriate bids to promote motor and social communication skills during each activity were } \\
\text { provided } \\
\text { Example: For building activity, "Let's roll the Play-Doh into a ball. Roll with me" }\end{array}$ \\
\hline Trials & Trainer asks child to repeat each activity twice \\
\hline Spontaneous exploration & $\begin{array}{l}\text { Trainer and model provide children with opportunities for free play and spontaneous exploration } \\
\text { Example: "It is free music time. You can play the drums in any way you want" }\end{array}$ \\
\hline Social praise & Trainer and model provide verbal and gestural praise to child as required \\
\hline Help with cleanup & Trainer and model ask child to help with cleanup of supplies after completion of each activity \\
\hline Activity completion & After each activity, trainer asks child to move down the picture for the activity on the PECS board \\
\hline General characteristics in the session & $\begin{array}{l}\text { The overall session is evaluated for the following characteristics: } \\
\text { number of activities completed, environmental arrangement (supplies in close proximity but out of } \\
\text { the sight of the child to avoid distractions), and incremental prompts (visual, verbal, gestural, and } \\
\text { lastly manual prompts/assistance provided if child is unable to perform the activity ) }\end{array}$ \\
\hline Trainer and model behaviors & $\begin{array}{l}\text { The trainer's and model's behaviors are evaluated for the following criteria on a scale of } 1 \text { to } 5 \text { : } \\
\text { (i) appropriateness of instructions, prompts, and reinforcement, } \\
\text { (ii) voice and affect modulation, } \\
\text { (iii) appropriateness of movements }\end{array}$ \\
\hline Child interest & Child's interest and compliance during session assessed on a scale of 1 to 5. \\
\hline
\end{tabular}

3.1.1. Between-Group Differences. At baseline, the comparison group had significantly greater scores on the fine manual control composite than the rhythm group (Rhythm: $\mathrm{M}(\mathrm{SD})=33.5$ (5.02), Comparison: $\mathrm{M}(\mathrm{SD})=41.44$ (8.72), $p=0.02)$. Based on the pretest session, there were no other baseline differences between groups on the body coordination and fine manual control composite standard scores. In the posttest session, after controlling for baseline levels of autism severity, the comparison group had significantly higher scores on the fine manual control composite compared to the robot and rhythm groups (Rhythm: $\mathrm{M}(\mathrm{SD})=$ 34.38 (4.36), Robot: $M(S D)=34.13$ (8.72), Comparison: $\mathrm{M}(\mathrm{SD})=44.52(10.82), p$ values $<0.02)($ see Figure $3(\mathrm{~b}))$.

3.1.2. Within-Group Changes. In the rhythm group, after controlling for baseline levels of autism severity, children 
TABLE 5: An exemplar rhythm, robot, and comparison group training session.

\begin{tabular}{|c|c|c|c|}
\hline Activity & Rhythm group & Robot group & Comparison group \\
\hline 1 & $\begin{array}{l}\text { Hello song } \\
\text { (i) Child asked to sing to trainer and } \\
\text { model } \\
\text { (ii) Song: hello everybody, yes indeed }\end{array}$ & $\begin{array}{l}\text { Introduction } \\
\text { Child asked to greet the trainer, model, } \\
\text { and robot }\end{array}$ & $\begin{array}{l}\text { Introduction } \\
\text { Child asked to greet the trainer and } \\
\text { model }\end{array}$ \\
\hline 2 & $\begin{array}{l}\text { Action song } \\
\text { (i) Child asked to sing and engage in } \\
\text { finger play } \\
\text { (ii) Song: open shut them }\end{array}$ & $\begin{array}{l}\text { Warm-up game } \\
\text { Child asked to copy whole-body } \\
\text { stretching moves of the Nao robot }\end{array}$ & $\begin{array}{l}\text { Book reading } \\
\text { Child reads age-appropriate book } \\
\text { while taking turns with trainer and } \\
\text { model }\end{array}$ \\
\hline 3 & $\begin{array}{l}\text { Beat keeping } \\
\text { (i) Child asked to copy trainer during } \\
\text { rhythmic arm and leg actions } \\
\text { (ii) Song: stop, go, go, go }\end{array}$ & $\begin{array}{l}\text { Action game } \\
\text { (i) Child asked to engage in upper and } \\
\text { lower body synchrony games with Nao } \\
\text { robot and model } \\
\text { (ii) Theme: start and stop game }\end{array}$ & $\begin{array}{l}\text { Building } \\
\text { (i) Child builds creations using } \\
\text { Play-Doh, Lego, and so forth } \\
\text { (ii) Theme: make a Lego car }\end{array}$ \\
\hline 4 & $\begin{array}{l}\text { Music making } \\
\text { (i) Child asked to play instruments like } \\
\text { drums, xylophones, cymbals, } \\
\text { tambourines, and so forth } \\
\text { (ii) Song: jingle jingle jingle jive }\end{array}$ & $\begin{array}{l}\text { Drumming game } \\
\text { (i) Child asked to practice simple and } \\
\text { complex drum patterns with Nao } \\
\text { robot and model } \\
\text { (ii) Theme: start and stop game }\end{array}$ & $\begin{array}{l}\text { Arts and crafts } \\
\text { (i) Child makes creations by drawing, } \\
\text { coloring, cutting, and so forth } \\
\text { (ii) Theme: make a vegetable basket }\end{array}$ \\
\hline 5 & $\begin{array}{l}\text { Moving game } \\
\text { (i) Child asked to copy trainer during } \\
\text { gross motor actions like skipping, } \\
\text { hopping, jumping, and so forth } \\
\text { (ii) Song: on the bridge of Newtown }\end{array}$ & $\begin{array}{l}\text { Walking } \\
\text { (i) Child asked to follow Rovio robot } \\
\text { with the model to trace letters and } \\
\text { shapes on the floor } \\
\text { (ii) Theme: tracing letter "L" }\end{array}$ & $\begin{array}{l}\text { Cleanup } \\
\text { Child asked to clean up all supplies } \\
\text { used for the session }\end{array}$ \\
\hline 6 & $\begin{array}{l}\text { Farewell song } \\
\text { (i) Child asked to sing to trainer and } \\
\text { model } \\
\text { (ii) Song: it was good to see you }\end{array}$ & $\begin{array}{l}\text { Farewell } \\
\text { Child asked to bid goodbye to the } \\
\text { trainer, model, and robot }\end{array}$ & $\begin{array}{l}\text { Farewell } \\
\text { Child asked to bid goodbye to trainer } \\
\text { and model }\end{array}$ \\
\hline
\end{tabular}

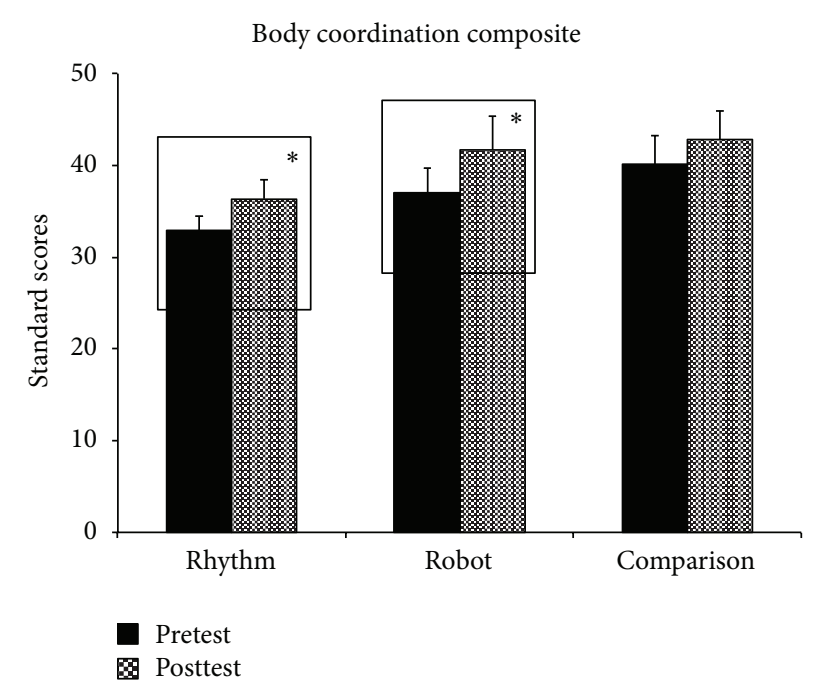

(a)

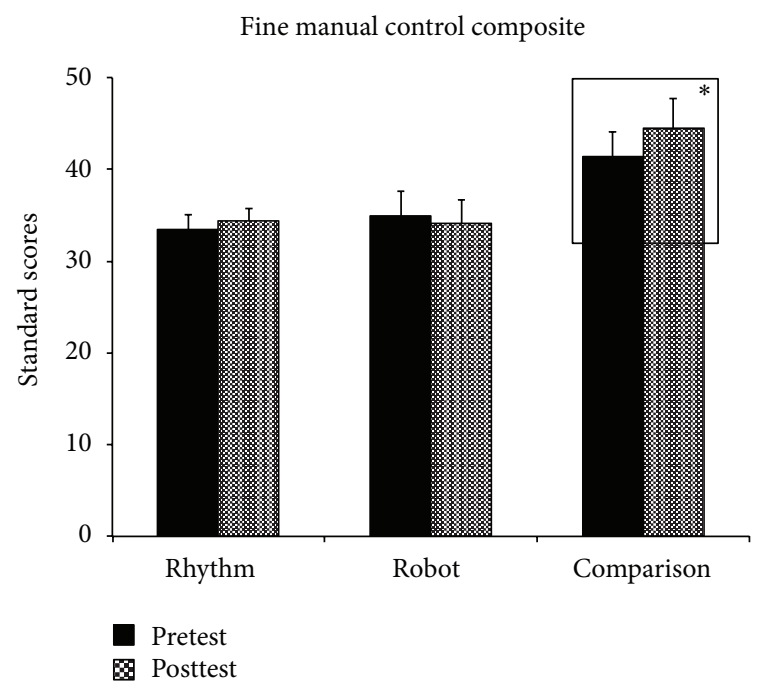

(b)

FIgURE 3: (a) Training-related changes on the body coordination composite of BOT-2. Error bars represent standard errors. (b) Trainingrelated changes on the fine manual control composite of BOT-2. Error bars represent standard errors. ${ }^{*} p \leq 0.05$.

improved their scores on the body coordination composite in the posttest compared to the pretest (Pretest: $M(\mathrm{SD})=$ 32.91 (5.34), Posttest: $M(S D)=36.36$ (6.90), $p=0.01$, SMD $=0.60)$ (see Figure 3(a)). Specifically, 9 out of 11 children followed the group trends. Similarly, in the robot group, children significantly improved their performance on the body coordination composite in the posttest compared to the pretest, while controlling for the effects of autism severity (Pretest: $M(S D)=37$ (9.15), Posttest: $M(S D)=$ 41.73 (12.02), $p=0.02, \mathrm{SMD}=0.48$ ) (see Figure $3(\mathrm{a})$ ). 
Specifically, 8 out of 11 children followed the group trends. Children in the rhythm and robot groups did not demonstrate any improvements in fine motor performance (see Figure 3(b)). In the comparison group, after controlling for baseline autism severity levels, children significantly increased their scores on the fine manual control composite of the BOT-2 from the pretest to the posttest session (Pretest: $\mathrm{M}(\mathrm{SD})=41.44$ (8.72), Posttest: $\mathrm{M}(\mathrm{SD})=44.52$ (10.83), $p=0.05, \mathrm{SMD}=0.33$ ) (see Figure $2(\mathrm{~b})$ ). Individual data show that 9 out of 11 children followed the group trends. This group did not show any improvements on the body coordination composite of the BOT-2 (see Figure 3(a)).

3.2. Training-Specific Test of Imitation/Praxis. In the rhythm group, children demonstrated a significant reduction in imitation error scores from the early to the late session (Early: $\mathrm{M}(\mathrm{SD})=35.55$ (26.85), Late: $\mathrm{M}(\mathrm{SD})=16.72$ (18.21), $t(23)=6.16, p<0.001, \mathrm{SMD}=-0.65)$ (see Figure 4). Individual data show that all 12 children in the group demonstrated improvements in imitation performance. In the robot group, children significantly improved imitation performance from the early to the late session (Early: $M(S D)=27.91$ (21.66), Late: $M(S D)=22.60$ (17.59), $t(23)=2.96, p=0.007, \mathrm{SMD}=-0.23$ ) (see Figure 4 ), with 10 out of the 12 children following the group trends. Along the same lines, the comparison group also demonstrated significant improvements in imitation performance from the early to the late session, with 9 out of 12 children following the group trend (Early: $M(S D)=24.85$ (20.69), Late: $M(S D)=$ $9.38(8.91), t(23)=4.77, p<0.001$, SMD $=-0.70)$ (see Figure 4).

3.3. Training-Specific Test of Interpersonal Synchrony. The repeated measures ANOVA in the rhythm group revealed main effects of session $\left(F(1,35)=4.57, p=0.04, \eta_{p}{ }^{2}=0.12\right)$ and synchrony type $(F(1.263,44.21)=51.98, p<0.001$, $\left.\eta_{p}{ }^{2}=0.60\right)$ as well as a significant session $x$ synchrony type interaction $\left(F(2,70)=3.99, p=0.023, \eta_{p}{ }^{2}=0.10\right)$. Post hoc analysis of the session $x$ synchrony type interaction showed that the rhythm group increased amount of time spent in-synchrony with the adult from the early to the late session (Early: $M(S D)=45.59$ (29.45), Late: $M(S D)=$ $52.91(30.57), p=0.02, \mathrm{SMD}=0.23$ ) (see Figure 5). Individual data show that 10 out of the 12 children followed the group trends.

The repeated measures ANOVA in the robot group showed a significant main effect of synchrony type $\left(F(1.35,47.22)=15.66, p<0.001, \eta_{p}{ }^{2}=0.31\right)$ and $a$ significant session $x$ synchrony type interaction $(F(2,70)=$ 3.78, $\left.p=0.028, \eta_{p}{ }^{2}=0.10\right)$. Post hoc analysis of the session $x$ synchrony type interaction indicated that the robot group increased the amount of time spent in-synchrony with the adult from the early to the late session (Early: $\mathrm{M}(\mathrm{SD})=37.88$ (28.55), Late: $\mathrm{M}(\mathrm{SD})=46.99$ (30.28), $p=0.04, \mathrm{SMD}=0.30)$, with 10 out of the 12 children following the group trends.

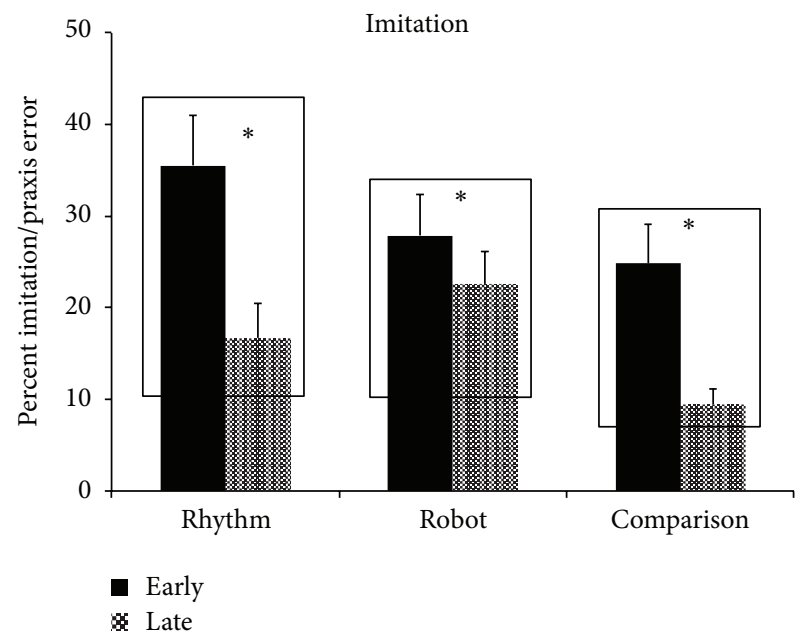

FIGURE 4: Training-related changes in percent imitation error in the rhythm, robot, and comparison groups. Error bars represent standard errors. ${ }^{*} p \leq 0.05$.

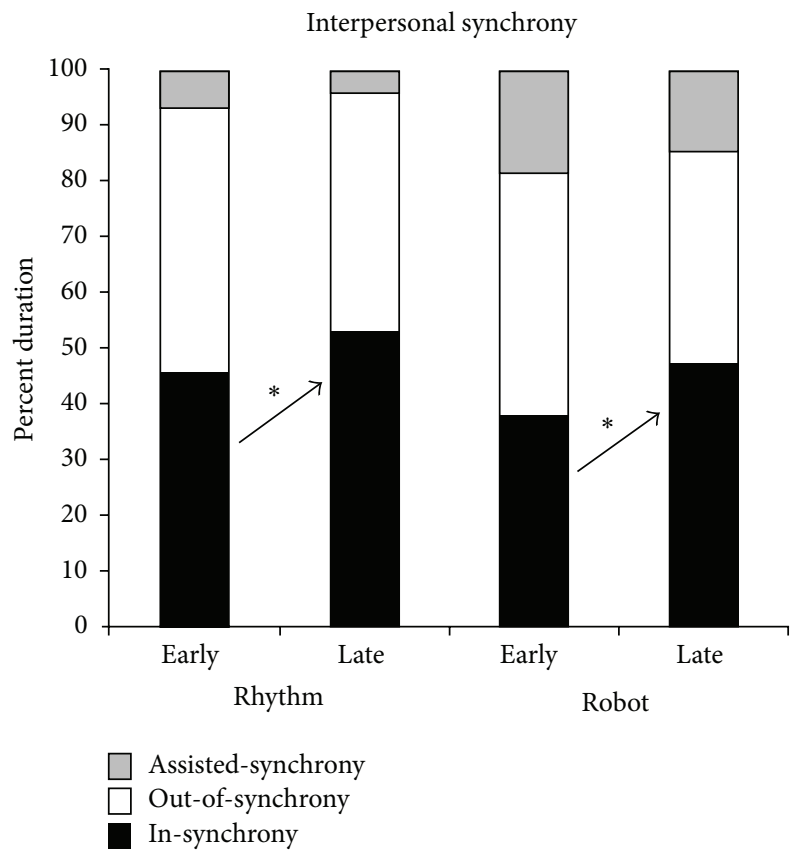

FIGURE 5: Training-related changes in interpersonal synchrony in the rhythm and robot groups. Error bars represent standard errors. ${ }^{*} p<0.05$.

\section{Discussion}

We examined the effects of rhythm and robotic interventions compared to a stationary comparison intervention on the gross and fine motor performance, imitation/praxis, and interpersonal synchrony skills of children with ASD. After controlling for the level of autism severity, the rhythm and robot groups demonstrated improvements in gross motor performance (i.e., body coordination composite) as measured on the BOT-2 from the pretest to the posttest session with no similar improvements on the fine manual 
control composite (see Figures 3(a) and 3(b)). Children in both groups also reduced their imitation/praxis errors and improved their interpersonal synchrony skills from the early to the late session (see Figures 4 and 5). Consistent with the type of training provided, the comparison group demonstrated an improvement on the fine manual control composite of the BOT-2 from the pretest to the posttest after controlling for level of autism severity, with no significant changes in gross motor performance (see Figures 3(a) and 3(b)). Moreover, children also significantly reduced their imitation errors from the early to the late session (see Figure 4). In the subsequent sections, we discuss possible reasons for our findings and also highlight the implications of our study results.

4.1. Changes in Motor Skills within the Standardized and Training-Specific Tests: Rhythm Group. The rhythm group demonstrated an improvement of medium effect size on the body coordination composite of the BOT-2 and the training-specific test of imitation/praxis as well as a small improvement on the training-specific test of interpersonal synchrony. Our findings fit with the limited existing literature on the use of music therapy in children with ASD and the broader music education literature on the effects of musicbased experiences on motor skills of TD children [75, 80, $81,104,105]$. For example, within the context of one-onone reciprocal musical imitation games involving musicmaking, singing, and dancing between children with autism and an adult therapist, 3 out of 4 children demonstrated an increase in spontaneous imitation of actions and words of the therapist [75]. In TD children, music has frequently been used as an accompaniment in physical education programs to improve balance and bilateral coordination skills [77, 79, 106, 107]. For example, a developmentally appropriate music and movement program led to greater improvements in jumping and dynamic balance skills of preschool children compared to a control group that engaged in physical education activities that were not based on music [78]. Similarly, following a music- and movement-based program, TD children improved dual and multilimb coordination skills during galloping, leaping, jumping, and skipping actions compared to a control group [107]. Along the same lines, prolonged musical training also led to improvement in accuracy on a motor sequencing task compared to a control group that did not receive musical instruction [80]. In terms of interpersonal synchrony, even 2.5-4.5 year old TD children were able to synchronize more accurately with their adult human partner compared to a machine during a joint drumming task [108]. Moreover, joint music making experiences such as singing or dancing foster prosocial cooperative/synchronous behaviors in 4-year old TD children [109]. Along these lines, the training activities in the rhythm group involved group-based symmetrical and asymmetrical movements of hands and legs such as jumping, galloping, hopping, and so forth to the beat of music. Across training weeks, children may have improved their visuomotor and bilateral coordination as well as balance skills, their ability to plan and execute multistep sequences, the speed and timing of their motor responses, and their ability to synchronize with social partners; this in turn could have led to improvements on standardized and training-specific measures of motor performance.

\subsection{Changes in Motor Skills within the Standardized and} Training-Specific Tests: Robot Group. The robot group also demonstrated small improvements in motor performance on the standardized and training-specific tests following training. Our previous proof-of-concept study on $14 \mathrm{TD}$ children and 1 child with autism suggested improvements in children's ability to coordinate actions with social partners following 4 weeks of imitation-based training using the 7inch humanoid robot, Isobot (Tony, Inc.) [92]. In the current study, we were able to replicate our previous work and further extend it to a larger sample of children with ASD. Our findings are also similar to the few other studies within the robotics literature that have used robots to facilitate motor skills in children with ASD [85-87, 110-112]. For example, children with ASD were faster at imitating a reach-to-grasp action following observation of a robotic versus a human model performing the task, whereas the reverse trend was observed in TD children [110]. Similarly, repeated short bouts of interactions with a humanoid doll robot, Robota, over 101 days led to a trend for improved imitation of simple actions of the robot in children with ASD [86]. In a different study, during repeated unconstrained interactions with a child-sized humanoid robot, KASPAR, a minimally expressive teenager with autism learned to imitate the actions of the robot as a part of turn taking games played with the therapist and another child [89]. Although the results of the above studies are encouraging, none of the aforementioned studies assessed motor performance using standardized tests or detailed coding schemes to evaluate changes in spatial and temporal aspects of movement execution following intervention. Our findings add to the current body of knowledge by systematically assessing motor performance using trainingspecific and standardized measures. Over training weeks, children may have improved their perception of the anthropomorphic characteristics of the robot, their balance, motor imitation, and multilimb coordination skills, as well as their social monitoring abilities; this could have contributed to the improvements in imitation/praxis, interpersonal synchrony, and overall gross motor performance seen in this group.

4.3. Changes in Motor Skills within the Standardized and Training-Specific Tests: Comparison Group. The comparison group demonstrated an improvement of small effect size on the fine motor subtests of the BOT-2 as well as an improvement of medium effect size on the training-specific test of imitation following the intervention. Our standard-ofcare comparison group was designed to mimic the kind of fine motor activities that children with ASD receive during school-based therapies [113]. These services typically address fine motor problems including handwriting skills (illegible writing, inability to stay on the line, letter reversals, etc.), desk skills (using scissors, folding, cutting, rolling PlayDoh, manipulating small objects, etc.), and organization skills (keeping materials in order, completing homework, remembering sequence of tasks, etc.) [114-116]. In line with the types of object manipulation, manual, and desk skills 
practiced during training sessions, the comparison group demonstrated improvements in fine motor skills. Our findings also fit with existing literature in children with fine motor problems that reports improvements in fine motor and visuomotor skills following prolonged interventions [115, 117]. For example, an 8-month intervention targeting fine motor problems in 44 preschool children led to improvements in standardized tests assessing in-hand manipulation, eyehand coordination, fine motor skills, visuomotor skills, and functional performance, with the amount of improvement associated with the intensity of training [115]. Similarly, at one-year follow-up following training to address fine motor, visuomotor, and gross motor skills, children with developmental disabilities showed improvements in visuomotor skills as assessed on standardized tests [117]. Overall, it was encouraging to see improvements in fine motor skills both within and outside the training context following a relatively short-term 8-week intervention program.

\section{Clinical Implications}

We assessed the effects of rhythm, robotic, and standard-ofcare comparison interventions on the gross and fine motor performance, imitation/praxis, and interpersonal synchrony skills of children with ASD between 5 and 12 years of age. Consistent with the training demands, the movement groups demonstrated improvements in balance, bilateral coordination, gross motor imitation, and interpersonal synchrony skills on standardized and training-specific tests following the 8-week intervention. Similarly, the comparison group demonstrated improvements in fine motor skills on the standardized BOT-2 test and the training-specific test of imitation. Given the association between motor impairments and core symptoms in ASD $[8,40,118]$, it would be critical to include both gross and fine motor goals in the treatment plan of children with ASD. Our data show that socially embedded movement-based contexts such as rhythm and robotic therapies that focus on imitation, bilateral coordination, balance, and synchrony skills are enjoyable for children and can be used to promote gross motor skills in this population. In fact, other data from this study show that movementbased contexts can also promote social communication skills such as social monitoring and verbal communication that are considered core impairments in autism. Therefore, in addition to the existing emphasis on remediating fine motor issues in children with ASD within predominantly sedentary contexts, socially embedded creative movement ideas involving rhythm, dance, and active play must also be introduced in the standard-of-care treatments for children with ASD.

We assessed the effects of interventions on trainingspecific as well as standardized tests of motor performance. The standardized test involved novel actions that were administered by a novel unfamiliar tester outside the training context during the pretest and posttest sessions. In contrast, the training-specific tests involved activities similar to the training activities and were administered by the familiar trainer within the training context during an early and late session. Improvements in the training-specific tests could therefore be attributed to some extent to familiarity effects. In contrast, improvements in the standardized test are indicative of carryover of skills learned during training sessions to novel contexts. It was encouraging to see that there were trainingrelated improvements in both standardized and trainingspecific tests in all three groups. Clinicians using similar movement-based games for children with ASD should aim to assess training-related changes in motor skills both within and outside the training context and should further evaluate sustenance of treatment effects at follow-up visits.

In the present study, although both rhythm and robot groups demonstrated improvements in motor skills, we observed several limitations in the robotic technology. First, the robot had a limited movement repertoire and could not train children for complex actions such as running, jumping, galloping, hopping, skipping, or even walking at different speeds. Secondly, the robot's movements were slower, less varied, and less precise than those of a human. Lastly, the robot could not train fine motor skills such as cutting, coloring, and drawing. Therefore, although our results look promising, at this point, we recommend that robots be used as adjunct therapies for children with ASD. Future efforts must be directed towards designing training activities that are engaging and functionally meaningful for children with autism, as well as developing contingent, semiautonomous robots that can adapt to the needs of the children.

\section{Limitations}

In spite of the promising results, our study is limited in many ways including a small sample size, limited intervention duration, limited generalization to activities of daily living, and lack of long-term follow-up. Our study was a preliminary study with a relatively small sample size of 36 children with 12 children per group. Further, there was some group variability in our sample due to the nature of the ASD diagnosis. In terms of behavioral coding, the coders of the trainingspecific measures were not blinded to the grouping of the child. The limited training duration of 8 weeks may have contributed to the small-to-moderate size improvements on the standardized and training-specific measures as well as the lack of significant between-group differences on the standardized BOT-2 test. Overall, in spite of the encouraging nature of our results, we recommend that they be interpreted with caution until future studies can replicate these results using larger sample sizes and extensive training protocols.

\section{Conclusions}

We assessed the effects of novel rhythm and robotic interventions compared to a standard-of-care comparison intervention on the gross and fine motor performance, imitation/praxis, and interpersonal synchrony skills of children with ASD. To the best of our knowledge, this is the first study to systematically assess the effects of rhythm and robotic interventions on motor skills of children using standardized motor tests and custom-developed coding schemes to evaluate imitation/praxis and interpersonal synchrony. Consistent with the training demands of the contexts, the movement groups demonstrated improvements in gross 
motor performance, whereas the comparison group demonstrated improvements in fine motor performance on the standardized BOT-2 test. All groups demonstrated improvements on the training-specific test of imitation and both the rhythm and robot groups improved their interpersonal synchrony performance following training. Overall, given the perceptuo-motor impairments in ASD, we argue for the inclusion of goals promoting gross and fine motor proficiency within the treatment plan of children with ASD. Our data showed that embodied, whole-body movementbased activities such as rhythm and robotic therapies are valuable contexts to promote motor skills in children with ASD.

\section{Disclosure}

This work was completed when Dr. Kerry L. Marsh was serving at the National Science Foundation.

\section{Disclaimer}

The views expressed here are solely of the authors and do not necessarily represent views of the National Science Foundation or the funding agencies, National Institutes of Health or Autism Speaks.

\section{Conflict of Interests}

All authors of this paper have no financial, personal, or professional conflict of interests to report at this time. The fourth author, Timothy D. Gifford, is commercializing the robotics technology developed in this study. Although he helped develop the technologies utilized in this project, he was not involved in the data collection, data analysis, or paper writing phases of this project.

\section{Acknowledgments}

The authors would like to thank the children and families who participated in this study. They thank Christian Wanamaker for his help with the programming of the Nao robot. They thank Dr. Linda Neelly for her support in developing the rhythm intervention protocol. They thank the undergraduate students who contributed to this project through data collection, data processing, and behavioral coding, Sara Balakrishnan, Margaret Reiss, Dominica Gilewska, Christina O'Hara, Chaitali Korgaonkar, Lyly Tran, Kathleen Lynch, Carolyn Susca, Sean Walsh, Debbie Lee, Cassondra Hunter, Tracy Sooklall, Caitlyn Metsack, Jenna Shaw, and Joanna Sajdlowska. They thank Dr. Marianne Barton, Director of the Psychological Services Clinic at the University of Connecticut, and clinical psychology doctoral students, Dasal Jashar and Lauren Haisley for their support in conducting ADOS testing. Last but not the least, they thank Dr. Deborah Bubela for her assistance with the testing and training administration for a subset of the participating children. The authors thank the National Institute of Mental Health for the R21MH089441 and R33MH089441 awards, Autism Speaks for the pilot treatment award \#8137, and the UConn Foundation for their large grant awarded to the last author, Dr. Anjana N. Bhat.

\section{References}

[1] American Psychiatric Association, Ed., Diagnostic and Statistical Manual of Mental Disorders, American Psychiatric Association, Arlington, Va, USA, 2013.

[2] G. Dawson, K. Toth, R. Abbott et al., "Early social attention impairments in autism: social orienting, joint attention, and attention to distress," Developmental Psychology, vol. 40, no. 2, pp. 271-283, 2004.

[3] H. Tager-Flusberg, R. Paul, and C. Lord, "Language and communication in autism," in Handbook of Autism and Pervasive Developmental Disorders, vol. 1, pp. 335-364, Wiley, 2005.

[4] S. R. Leekam, M. R. Prior, and M. Uljarevic, "Restricted and repetitive behaviors in autism spectrum disorders: a review of research in the last decade," Psychological Bulletin, vol. 137, no. 4, pp. 562-593, 2011.

[5] A. N. Bhat, R. J. Landa, and J. C. Galloway, "Current perspectives on motor functioning in infants, children, and adults with autism spectrum disorders," Physical Therapy, vol. 91, no. 7, pp. 1116-1129, 2011.

[6] M. Hallett, M. K. Lebiedowska, S. L. Thomas, S. J. Stanhope, M. B. Denckla, and J. Rumsey, "Locomotion of autistic adults," Archives of Neurology, vol. 50, no. 12, pp. 1304-1308, 1993.

[7] D. Green, T. Charman, A. Pickles et al., "Impairment in movement skills of children with autistic spectrum disorders," Developmental Medicine \& Child Neurology, vol. 51, no. 4, pp. 311-316, 2009.

[8] C. L. Hilton, Y. Zhang, M. R. Whilte, C. L. Klohr, and J. Constantino, "Motor impairment in sibling pairs concordant and discordant for autism spectrum disorders," Autism, vol. 16, no. 4, pp. 430-441, 2012.

[9] B. Provost, S. Heimerl, and B. R. Lopez, "Levels of gross and fine motor development in young children with autism spectrum disorder," Physical and Occupational Therapy in Pediatrics, vol. 27, no. 3, pp. 21-36, 2007.

[10] K. A. Fournier, C. J. Hass, S. K. Naik, N. Lodha, and J. H. Cauraugh, "Motor coordination in autism spectrum disorders: a synthesis and meta-analysis," Journal of Autism and Developmental Disorders, vol. 40, no. 10, pp. 1227-1240, 2010.

[11] S. J. Rogers, L. Bennetto, R. McEvoy, and B. F. Pennington, "Imitation and pantomime in high-functioning adolescents with autism spectrum disorders," Child Development, vol. 67, no. 5, pp. 2060-2073, 1996.

[12] R. P. Hobson and A. Lee, "Imitation and identification in autism," Journal of Child Psychology and Psychiatry, vol. 40, no. 4, pp. 649-659, 1999.

[13] G. Vivanti, D. Trembath, and C. Dissanayake, "Mechanisms of imitation impairment in autism spectrum disorder," Journal of Abnormal Child Psychology, vol. 42, no. 8, pp. 1395-1405, 2014.

[14] K. L. Marsh, R. W. Isenhower, M. J. Richardson et al., "Autism and social disconnection in interpersonal rocking," Frontiers in Integrative Neuroscience, vol. 7, 2013.

[15] L. R. Dowell, E. M. Mahone, and S. H. Mostofsky, "Associations of postural knowledge and basic motor skill with dyspraxia in autism: implication for abnormalities in distributed connectivity and motor learning," Neuropsychology, vol. 23, no. 5, pp. 563570, 2009. 
[16] M. R. Leary and D. A. Hill, "Moving on: autism and movement disturbance," Mental Retardation, vol. 34, no. 1, pp. 39-53, 1996.

[17] M. A. Gernsbacher, J. L. Stevenson, S. Khandakar, and H. H. Goldsmith, "Why does joint attention look atypical in autism?" Child Development Perspectives, vol. 2, no. 1, pp. 38-45, 2008.

[18] M. Lloyd, M. MacDonald, and C. Lord, "Motor skills of toddlers with autism spectrum disorders," Autism, vol. 17, no. 2, pp. 133146, 2013.

[19] C.-Y. Pan, C.-L. Tsai, and C.-H. Chu, "Fundamental movement skills in children diagnosed with autism spectrum disorders and attention deficit hyperactivity disorder," Journal of Autism and Developmental Disorders, vol. 39, no. 12, pp. 1694-1705, 2009.

[20] E. M. Jansiewicz, M. C. Goldberg, C. J. Newschaffer, M. B. Denckla, R. Landa, and S. H. Mostofsky, "Motor signs distinguish children with high functioning autism and Asperger's syndrome from controls," Journal of Autism and Developmental Disorders, vol. 36, no. 5, pp. 613-621, 2006.

[21] S. Sutera, J. Pandey, E. L. Esser et al., "Predictors of optimal outcome in toddlers diagnosed with autism spectrum disorders," Journal of Autism and Developmental Disorders, vol. 37, no. 1, pp. 98-107, 2007.

[22] R. Landa and E. Garrett-Mayer, "Development in infants with autism spectrum disorders: a prospective study," Journal of Child Psychology and Psychiatry, vol. 47, no. 6, pp. 629-638, 2006.

[23] J. E. Flanagan, R. Landa, A. Bhat, and M. Bauman, "Head lag in infants at risk for autism: a preliminary study," The American Journal of Occupational Therapy, vol. 66, no. 5, pp. 577-585, 2012.

[24] S. Ozonoff, S. Macari, G. S. Young, S. Goldring, M. Thompson, and S. J. Rogers, "Atypical object exploration at 12 months of age is associated with autism in a prospective sample," Autism, vol. 12, no. 5, pp. 457-472, 2008.

[25] G. Esposito, P. Venuti, S. Maestro, and F. Muratori, "An exploration of symmetry in early autism spectrum disorders: analysis of lying," Brain and Development, vol. 31, no. 2, pp. 131-138, 2009.

[26] R. W. Isenhower, K. L. Marsh, M. J. Richardson, M. Helt, R. C. Schmidt, and D. Fein, "Rhythmic bimanual coordination is impaired in young children with autism spectrum disorder," Research in Autism Spectrum Disorders, vol. 6, no. 1, pp. 25-31, 2012.

[27] J. L. Adrien, P. Lenoir, J. Martineau et al., "Blind ratings of early symptoms of autism based upon family home movies," Journal of the American Academy of Child \& Adolescent Psychiatry, vol. 32, no. 3, pp. 617-626, 1993.

[28] P. Teitelbaum, O. Teitelbaum, J. Nye, J. Fryman, and R. G. Maurer, "Movement analysis in infancy may be useful for early diagnosis of autism," Proceedings of the National Academy of Sciences of the United States of America, vol. 95, no. 23, pp. 13982-13987, 1998.

[29] C. M. Freitag, C. Kleser, M. Schneider, and A. von Gontard, "Quantitative assessment of neuromotor function in adolescents with high functioning autism and Asperger syndrome," Journal of Autism and Developmental Disorders, vol. 37, no. 5, pp. 948-959, 2007.

[30] N. J. Minshew, K. Sung, B. L. Jones, and J. M. Furman, "Underdevelopment of the postural control system in autism," Neurology, vol. 63, no. 11, pp. 2056-2061, 2004.

[31] N. J. Rinehart, M. A. Bellgrove, B. J. Tonge, A. V. Brereton, D. Howells-Rankin, and J. L. Bradshaw, "An examination of movement kinematics in young people with high-functioning autism and Asperger's disorder: further evidence for a motor planning deficit," Journal of Autism and Developmental Disorders, vol. 36, no. 6, pp. 757-767, 2006.

[32] J. A. Vilensky, A. R. Damasio, and R. G. Maurer, "Gait disturbances in patients with autistic behavior: a preliminary study," Archives of Neurology, vol. 38, no. 10, pp. 646-649, 1981.

[33] S. L. Berkeley, L. L. Zittel, L. V. Pitney, and S. E. Nichols, "Locomotor and object control skills of children diagnosed with autism," Adapted Physical Activity Quarterly, vol. 18, no. 4, pp. 405-416, 2001.

[34] D. Green, G. Baird, A. L. Barnett, L. Henderson, J. Huber, and S. E. Henderson, "The severity and nature of motor impairment in Asperger's syndrome: a comparison with specific developmental disorder of motor function," Journal of Child Psychology and Psychiatry and Allied Disciplines, vol. 43, no. 5, pp. 655-668, 2002.

[35] M. Miyahara, M. Tsujii, M. Hori, K. Nakanishi, H. Kageyama, and T. Sugiyama, "Brief report: motor incoordination in children with Asperger syndrome and learning disabilities," Journal of Autism and Developmental Disorders, vol. 27, no. 5, pp. 595603, 1997.

[36] L.-A. R. Sacrey, T. Germani, S. E. Bryson, and L. Zwaigenbaum, "Reaching and grasping in autism spectrum disorder: a review of recent literature," Frontiers in Neurology, vol. 5, article 6, 2014.

[37] A. Kushki, T. Chau, and E. Anagnostou, "Handwriting difficulties in children with autism spectrum disorders: a scoping review," Journal of Autism and Developmental Disorders, vol. 41, no. 12, pp. 1706-1716, 2011.

[38] C. T. Fuentes, S. H. Mostofsky, and A. J. Bastian, "Children with autism show specific handwriting impairments," Neurology, vol. 73, no. 19, pp. 1532-1537, 2009.

[39] S. Dickerson Mayes and S. L. Calhoun, "Ability profiles in children with autism: influence of age and IQ," Autism, vol. 7, no. 1, pp. 65-80, 2003.

[40] M. A. Dziuk, J. C. G. Larson, A. Apostu, E. M. Mahone, M. B. Denckla, and S. H. Mostofsky, "Dyspraxia in autism: association with motor, social, and communicative deficits," Developmental Medicine \& Child Neurology, vol. 49, no. 10, pp. 734-739, 2007.

[41] S. Kopp, E. Beckung, and C. Gillberg, "Developmental coordination disorder and other motor control problems in girls with autism spectrum disorder and/or attentiondeficit/hyperactivity disorder," Research in Developmental Disabilities, vol. 31, no. 2, pp. 350-361, 2010.

[42] A. Kleinspehn-Ammerlahn, M. Riediger, F. Schmiedek, T. von Oertzen, S.-C. Li, and U. Lindenberger, "Dyadic drumming across the lifespan reveals a zone of proximal development in children," Developmental Psychology, vol. 47, no. 3, pp. 632-644, 2011.

[43] C. Colombi, K. Liebal, M. Tomasello, G. Young, F. Warneken, and S. J. Rogers, "Examining correlates of cooperation in autism: imitation, joint attention, and understanding intentions," Autism, vol. 13, no. 2, pp. 143-163, 2009.

[44] K. L. Marsh, M. J. Richardson, and R. C. Schmidt, "Social connection through joint action and interpersonal coordination," Topics in Cognitive Science, vol. 1, no. 2, pp. 320-339, 2009.

[45] P. Fitzpatrick, R. Diorio, M. J. Richardson, and R. C. Schmidt, "Dynamical methods for evaluating the time-dependent unfolding of social coordination in children with autism," Frontiers in Integrative Neuroscience, vol. 7, article 21, 2013.

[46] A. McDuffie, L. Turner, W. Stone, P. Yoder, M. Wolery, and T. Ulman, "Developmental correlates of different types of motor 
imitation in young children with autism spectrum disorders," Journal of Autism and Developmental Disorders, vol. 37, no. 3, pp. 401-412, 2007.

[47] N. I. Berger and B. Ingersoll, "An exploration of imitation recognition in young children with autism spectrum disorders," Autism Research, vol. 6, no. 5, pp. 411-416, 2013.

[48] T. Charman, J. Swettenham, S. Baron-Cohen, A. Cox, G. Baird, and A. Drew, "Infants with autism: an investigation of empathy, pretend play, joint attention, and imitation," Developmental Psychology, vol. 33, no. 5, pp. 781-789, 1997.

[49] W. L. Stone, O. Y. Ousley, and C. D. Littleford, "Motor imitation in young children with autism: what's the object?" Journal of Abnormal Child Psychology, vol. 25, no. 6, pp. 475-485, 1997.

[50] R. Bernier, G. Dawson, S. Webb, and M. Murias, "EEG mu rhythm and imitation impairments in individuals with autism spectrum disorder," Brain and Cognition, vol. 64, no. 3, pp. 228237, 2007.

[51] S. Avikainen, A. Wohlschläger, S. Liuhanen, R. Hänninen, and R. Hari, "Impaired mirror-image imitation in Asperger and high-functioning autistic subjects," Current Biology, vol. 13, no. 4, pp. 339-341, 2003.

[52] A. N. Meltzoff and A. Gopnik, "The role of imitation in understanding persons and developing a theory of mind," in Understanding Other Minds: Perspectives from Autism, pp. 335366, Oxford University Press, Oxford, UK, 1993.

[53] S. J. Rogers and B. F. Pennington, "A theoretical approach to the deficits in infantile autism," Development and Psychopathology, vol. 3, no. 2, pp. 137-162, 1991.

[54] I. M. Smith and S. E. Bryson, "Imitation and action in autism: a critical review," Psychological Bulletin, vol. 116, no. 2, pp. 259273, 1994.

[55] J. H. G. Williams, A. Whiten, and T. Singh, "A systematic review of action imitation in autistic spectrum disorder," Journal of Autism and Developmental Disorders, vol. 34, no. 3, pp. 285-299, 2004.

[56] M. Vanvuchelen, H. Roeyers, and W. De Weerdt, "Nature of motor imitation problems in school-aged boys with autism: a motor or a cognitive problem?" Autism, vol. 11, no. 3, pp. 225240, 2007.

[57] D. Dewey, M. Cantell, and S. G. Crawford, "Motor and gestural performance in children with autism spectrum disorders, developmental coordination disorder, and/or attention deficit hyperactivity disorder," Journal of the International Neuropsychological Society, vol. 13, no. 2, pp. 246-256, 2007.

[58] S. H. Mostofsky, P. Dubey, V. K. Jerath, E. M. Jansiewicz, M. C. Goldberg, and M. B. Denckla, "Developmental dyspraxia is not limited to imitation in children with autism spectrum disorders," Journal of the International Neuropsychological Society, vol. 12, no. 3, pp. 314-326, 2006.

[59] B. Ingersoll and K. Meyer, "Examination of correlates of different imitative functions in young children with autism spectrum disorders," Research in Autism Spectrum Disorders, vol. 5, no. 3, pp. 1078-1085, 2011.

[60] K. Toth, J. Munson, A. N. Meltzoff, and G. Dawson, "Early predictors of communication development in young children with autism spectrum disorder: joint attention, imitation, and toy play," Journal of Autism and Developmental Disorders, vol. 36, no. 8, pp. 993-1005, 2006.

[61] D. A. Zachor, T. Ilanit, and E. B. Itzchak, "Autism severity and motor abilities correlates of imitation situations in children with autism spectrum disorders," Research in Autism Spectrum Disorders, vol. 4, no. 3, pp. 438-443, 2010.
[62] B. Ingersoll and L. Schreibman, "Teaching reciprocal imitation skills to young children with autism using a naturalistic behavioral approach: effects on language, pretend play, and joint attention," Journal of Autism and Developmental Disorders, vol. 36, no. 4, pp. 487-505, 2006.

[63] R. J. Landa, K. C. Holman, A. H. O'Neill, and E. A. Stuart, "Intervention targeting development of socially synchronous engagement in toddlers with autism spectrum disorder: a randomized controlled trial," Journal of Child Psychology and Psychiatry, vol. 52, no. 1, pp. 13-21, 2011.

[64] E. G. Carr and M. Darcy, "Setting generality of peer modeling in children with autism," Journal of Autism and Developmental Disorders, vol. 20, no. 1, pp. 45-59, 1990.

[65] A. N. Garfinkle and I. S. Schwartz, "Peer imitation: increasing social interactions in children with autism and other developmental disabilities in inclusive preschool classrooms," Topics in Early Childhood Special Education, vol. 22, no. 1, pp. 26-38, 2002.

[66] M. H. Charlop-Christy, L. Le, and K. A. Freeman, "A comparison of video modeling with in vivo modeling for teaching children with autism," Journal of Autism and Developmental Disorders, vol. 30, no. 6, pp. 537-552, 2000.

[67] B. Ingersoll, "Brief report: pilot randomized controlled trial of reciprocal imitation training for teaching elicited and spontaneous imitation to children with autism," Journal of Autism and Developmental Disorders, vol. 40, no. 9, pp. 1154-1160, 2010.

[68] K. Simpson and D. Keen, "Music interventions for children with autism: narrative review of the literature," Journal of Autism and Developmental Disorders, vol. 41, no. 11, pp. 1507-1514, 2011.

[69] J. Whipple, "Music in intervention for children and adolescents with autism: a meta-analysis," Journal of Music Therapy, vol. 41, no. 2, pp. 90-106, 2004.

[70] J. J. Diehl, L. M. Schmitt, M. Villano, and C. R. Crowell, “The clinical use of robots for individuals with Autism Spectrum Disorders: a critical review," Research in Autism Spectrum Disorders, vol. 6, no. 1, pp. 249-262, 2012.

[71] P. Heaton, B. Hermelin, and L. Pring, "Can children with autistic spectrum disorders perceive affect in music? An experimental investigation," Psychological Medicine, vol. 29, no. 6, pp. 14051410, 1999.

[72] A. Bonnel, L. Mottron, I. Peretz, M. Trudel, E. Gallun, and A.-M. Bonnel, "Enhanced pitch sensitivity in individuals with autism: a signal detection analysis," Journal of Cognitive Neuroscience, vol. 15, no. 2, pp. 226-235, 2003.

[73] M. Geretsegger, C. Elefant, K. A. Mössler, and C. Gold, "Music therapy for people with autism spectrum disorder," Cochrane Database of Systematic Reviews, no. 6, Article ID CD004381, pp. 1-23, 2014.

[74] S. M. Srinivasan and A. N. Bhat, "A review of 'music and movement' therapies for children with autism: embodied interventions for multisystem development," Frontiers in Integrative Neuroscience, vol. 7, article 22, 2013.

[75] C. E. Stephens, "Spontaneous imitation by children with autism during a repetitive musical play routine," Autism, vol. 12, no. 6, pp. 645-671, 2008.

[76] E. M. Buday, "The effects of signed and spoken words taught with music on sign and speech imitation by children with autism," Journal of Music Therapy, vol. 32, no. 3, pp. 189-202, 1995.

[77] E. Deli, I. Bakle, and E. Zachopoulou, "Implementing intervention movement programs for kindergarten children," Journal of Early Childhood Research, vol. 4, no. 1, pp. 5-18, 2006. 
[78] E. Zachopoulou, A. Tsapakidou, and V. Derri, “The effects of a developmentally appropriate music and movement program on motor performance," Early Childhood Research Quarterly, vol. 19, no. 4, pp. 631-642, 2004.

[79] V. Derri, A. Tsapakidou, E. Zachopoulou, and E. Kioumourtzoglou, "Effect of a music and movement programme on development of locomotor skills by children 4 to 6 years of age," European Journal of Physical Education, vol. 6, no. 1, pp. 16-25, 2001.

[80] M. Forgeard, E. Winner, A. Norton, and G. Schlaug, "Practicing a musical instrument in childhood is associated with enhanced verbal ability and nonverbal reasoning," PLoS ONE, vol. 3, no. 10, Article ID e3566, 2008.

[81] E. Costa-Giomi, "Does music instruction improve fine motor abilities?" Annals of the New York Academy of Sciences, vol. 1060, pp. 262-264, 2005.

[82] B. B. Scassellati, "How social robots will help us to diagnose, treat, and understand autism," in Robotics Research: Results of the 12th International Symposium ISRR, vol. 28 of Springer Tracts in Advanced Robotics, pp. 552-563, Springer, Berlin, Germany, 2007.

[83] B. Robins, K. Dautenhahn, R. Te Boekhorst, and A. Billard, "Robotic assistants in therapy and education of children with autism: can a small humanoid robot help encourage social interaction skills?" Universal Access in the Information Society, vol. 4, no. 2, pp. 105-120, 2005.

[84] A. Tapus, M. J. Mataric, and B. Scassellati, "Socially assistive robotics [Grand Challenges of Robotics]," IEEE Robotics \& Automation Magazine, vol. 14, no. 1, pp. 35-42, 2007.

[85] A. Duquette, F. Michaud, and H. Mercier, "Exploring the use of a mobile robot as an imitation agent with children with lowfunctioning autism," Autonomous Robots, vol. 24, no. 2, pp. 147157, 2008.

[86] B. Robins, K. Dautenhahn, R. te Boekhorst, and A. Billard, "Effects of repeated exposure to a humanoid robot on children with autism," in Universal Access and Assistive Technology, Springer, Cambrige, UK, 2004.

[87] I. Fujimoto, T. Matsumoto, P. R. De Silva, M. Kobayashi, and M. Higashi, "Mimicking and evaluating human motion to improve the imitation skill of children with autism through a robot," International Journal of Social Robotics, vol. 3, no. 4, pp. 349357, 2011.

[88] H. Kozima, C. Nakagawa, and Y. Yasuda, "Children-robot interaction: a pilot study in autism therapy," Progress in Brain Research, vol. 164, pp. 385-400, 2007.

[89] B. Robins, K. Dautenhahn, and P. Dickerson, "From isolation to communication: a case study evaluation of robot assisted play for children with autism with a minimally expressive humanoid robot," in Proceedings of the 2nd International Conferences on Advances in Computer-Human Interactions (ACHI '09), pp. 205-211, IEEE, Cancún, Mexico, February 2009.

[90] B. Scassellati, H. Admoni, and M. Matarić, "Robots for use in autism research," Annual Review of Biomedical Engineering, vol. 14, no. 1, pp. 275-294, 2012.

[91] S. M. Srinivasan, K. A. Lynch, D. J. Bubela, T. D. Gifford, and A. N. Bhat, "Effect of interactions between a child and a robot on the imitation and praxis performance of typically devloping children and a child with autism: a preliminary study," Perceptual and Motor Skills, vol. 116, no. 3, pp. 885-904, 2013.

[92] M. Kaur, T. Gifford, K. L. Marsh, and A. Bhat, "Effect of robotchild interactions on bilateral coordination skills of typically developing children and a child with autism spectrum disorder: a preliminary study," Journal of Motor Learning and Development, vol. 1, no. 2, pp. 31-37, 2013.

[93] R. Bruininks and B. Bruininks, Bruininks-Oseretsky Test of Motor Proficiency Second Edition (BOT2), AGS Publishing, Circle Pines, Minn, USA, 2005.

[94] M. Rutter, A. Bailey, and C. Lord, The Social Communication Questionnaire: Manual, Western Psychological Services, 2003.

[95] C. Lord, M. Rutter, P. C. DiLavore, S. Risi, K. Gotham, and S. L. Bishop, Autism Diagnostic Observation Schedule, Second Edition (ADOS-2) Manual (Part 1): Modules 1-4, Western Psychological Services, Torrance, Calif, USA, 2012.

[96] A. Hollingshead, Four Factor Index of Social Status, Yale University, New Haven, Conn, USA, 1975.

[97] S. S. Sparrow, D. V. Cicchetti, and D. A. Balla, The Vineland Adaptive Behavior Scales, Springer, 2005.

[98] S. E. Henderson, D. A. Sugden, and A. L. Barnett, Movement Assessment Battery for Children-2: Movement ABC-2: Examiner's Manual, Pearson, 2007.

[99] O. I. Lovaas, "Behavioral treatment and normal educational and intellectual functioning in young autistic children," Journal of Consulting and Clinical Psychology, vol. 55, no. 1, pp. 3-9, 1987.

[100] G. B. Mesibov, V. Shea, and E. Schopler, The TEACCH Approach to Autism Spectrum Disorders, Springer, New York, NY, USA, 2004.

[101] A. Bondy and A. Frost, "Communication strategies for visual learners," in Teaching Individuals with Developmental Delays: Basic Intervention Techniques, O. I. Lovaas, Ed., pp. 291-304, PRO-ED, Austin, Tex, USA, 2003.

[102] D. Dewey, "Error analysis of limb and orofacial praxis in children with developmental motor deficits," Brain and Cognition, vol. 23, no. 2, pp. 203-221, 1993.

[103] L. V. Hedges, "Distribution theory for Glass's estimator of effect size and related estimators," Journal of Educational and Behavioral Statistics, vol. 6, no. 2, pp. 107-128, 1981.

[104] E. Costa-Giomi, "Effects of three years of piano instruction on children's academic achievement, school performance and selfesteem," Psychology of Music, vol. 32, no. 2, pp. 139-152, 2004.

[105] I. Hurwitz, P. H. Wolff, B. D. Bortnick, and K. Kokas, "Nonmusicol effects of the Kodaly music curriculum in primary grade children," Journal of Learning Disabilities, vol. 8, no. 3, pp. 167174, 1975.

[106] J. Brown, C. Sherrill, and B. Gench, "Effects of an integrated physical education/music program in changing early childhood perceptual-motor performance," Perceptual and Motor Skills, vol. 53, no. 1, pp. 151-154, 1981.

[107] B. Ulrich and D. Ulrich, "The role of balancing ability in performance of fundamental motor skills in 3-, 4-, 5-year-old children," Motor Development: Current Selected Research, vol. 1, pp. 87-97, 1985.

[108] S. Kirschner and M. Tomasello, "Joint drumming: social context facilitates synchronization in preschool children," Journal of Experimental Child Psychology, vol. 102, no. 3, pp. 299-314, 2009.

[109] S. Kirschner and M. Tomasello, "Joint music making promotes prosocial behavior in 4-year-old children," Evolution and Human Behavior, vol. 31, no. 5, pp. 354-364, 2010.

[110] A. C. Pierno, M. Mari, D. Lusher, and U. Castiello, "Robotic movement elicits visuomotor priming in children with autism," Neuropsychologia, vol. 46, no. 2, pp. 448-454, 2008.

[111] D. Hanson, D. Mazzei, C. Garver et al., "Realistic humanlike robots for treatment of ASD, social training, and research; 
shown to appeal to youths with ASD, cause physiological arousal, and increase human-to-human social engagement," in Proceedings of the 5th ACM International Conference on Pervasive Technologies Related to Assistive Environments (PETRA '12), Heraklion, Greece, June 2012.

[112] G. Pioggia, R. Igliozzi, M. L. Sica et al., "Exploring emotional and imitational android-based interactions in autistic spectrum disorders," Journal of Cyber Therapy \& Rehabilitation, vol. 1, no. 1, pp. 49-61, 2008.

[113] J. Case-Smith and H. Miller, "Occupational therapy with children with pervasive developmental disorders," American Journal of Occupational Therapy, vol. 53, no. 5, pp. 506-513, 1999.

[114] D. Reid, T. Chiu, G. Sinclair, S. Wehrmann, and Z. Naseer, "Outcomes of an occupational therapy school-based consultation service for students with fine motor difficulties," Canadian Journal of Occupational Therapy, vol. 73, no. 4, pp. 215-224, 2006.

[115] J. Case-Smith, "Effectiveness of school-based occupational therapy intervention on handwriting," American Journal of Occupational Therapy, vol. 56, no. 1, pp. 17-25, 2002.

[116] K. McHale and S. A. Cermak, "Fine motor activities in elementary school: preliminary findings and provisional implications for children with fine motor problems," American Journal of Occupational Therapy, vol. 46, no. 10, pp. 898-903, 1992.

[117] H. L. Dankert, P. L. Davies, and W. J. Gavin, "Occupational therapy effects on visual-motor skills in preschool children," American Journal of Occupational Therapy, vol. 57, no. 5, pp. 542-549, 2003.

[118] C. Hilton, L. Wente, P. LaVesser, M. Ito, C. Reed, and G. Herzberg, "Relationship between motor skill impairment and severity in children with Asperger syndrome," Research in Autism Spectrum Disorders, vol. 1, no. 4, pp. 339-349, 2007. 


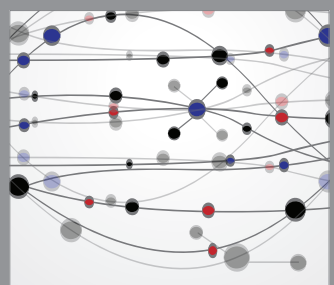

The Scientific World Journal
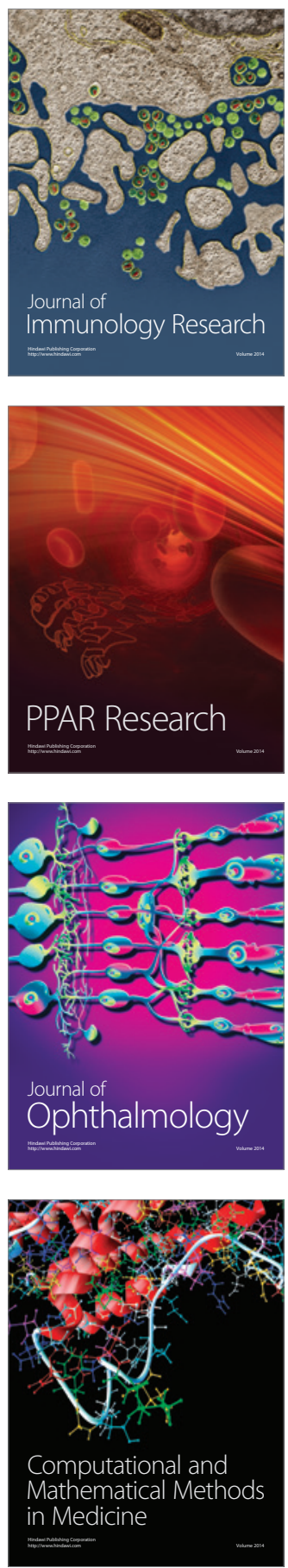

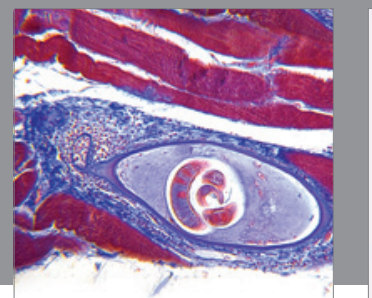

Gastroenterology

Research and Practice
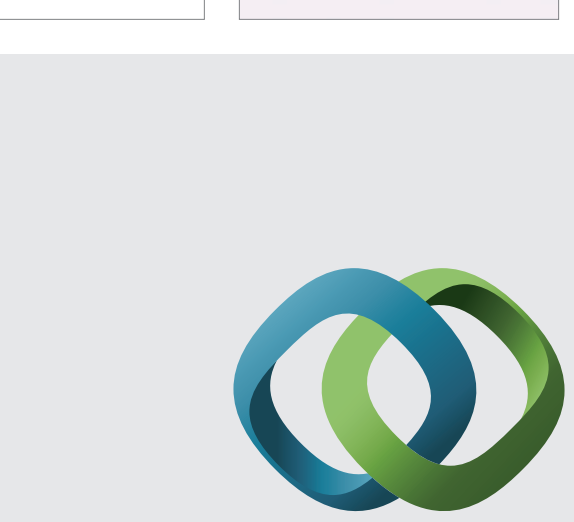

\section{Hindawi}

Submit your manuscripts at

http://www.hindawi.com
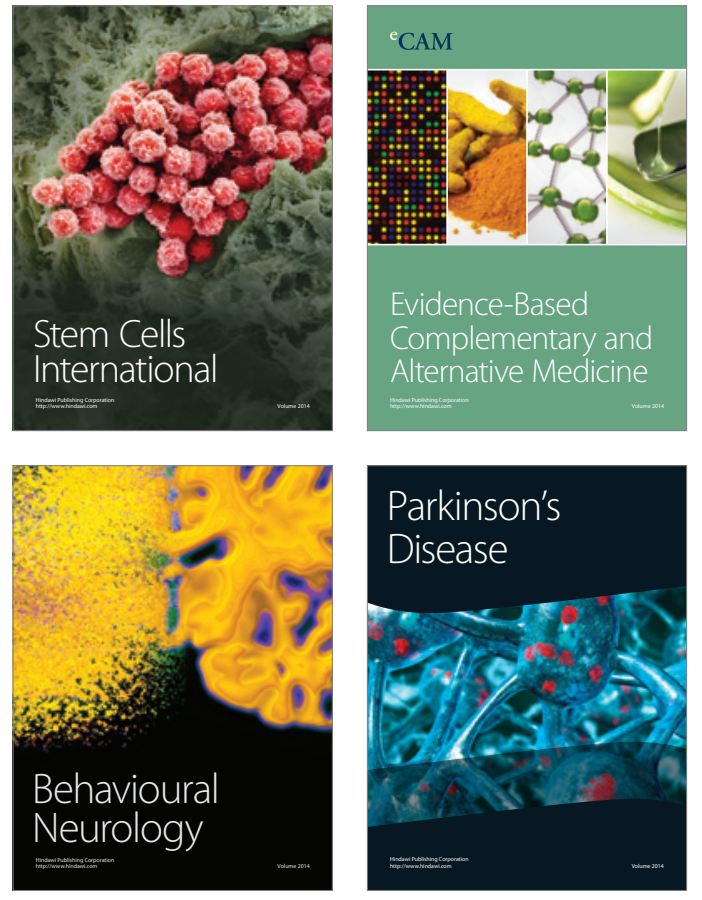
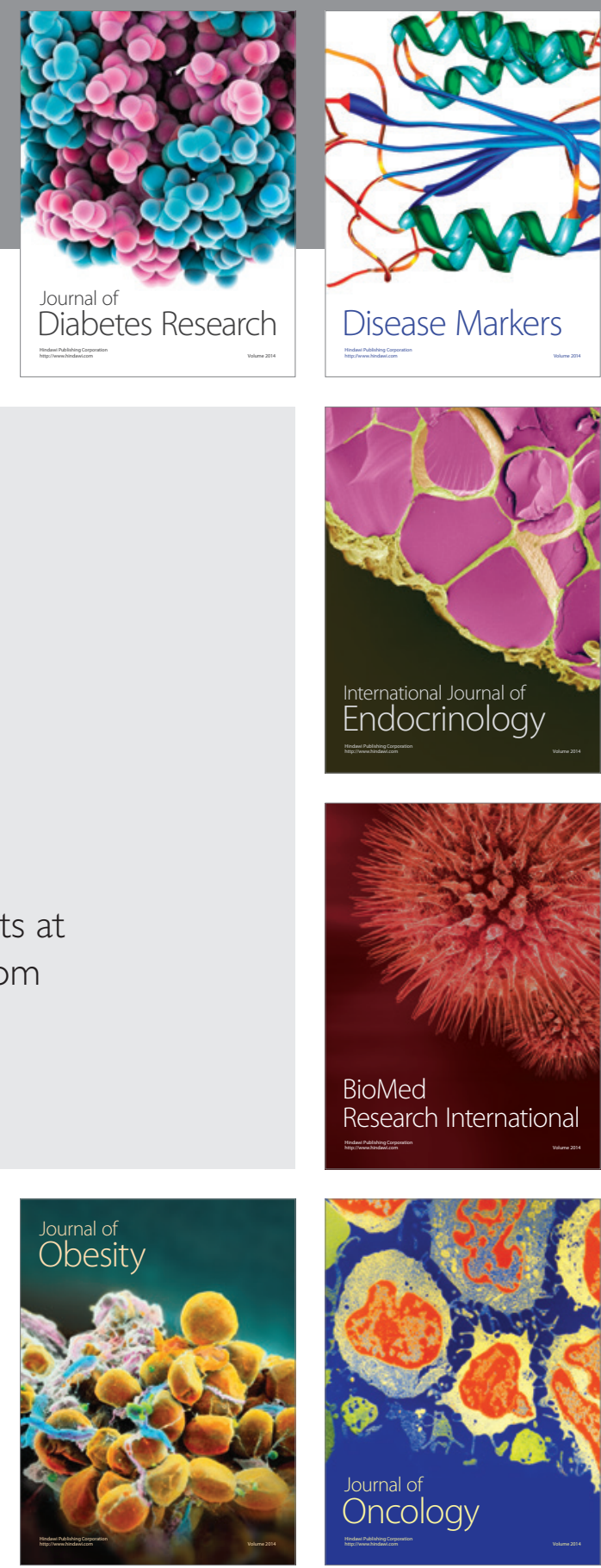

Disease Markers
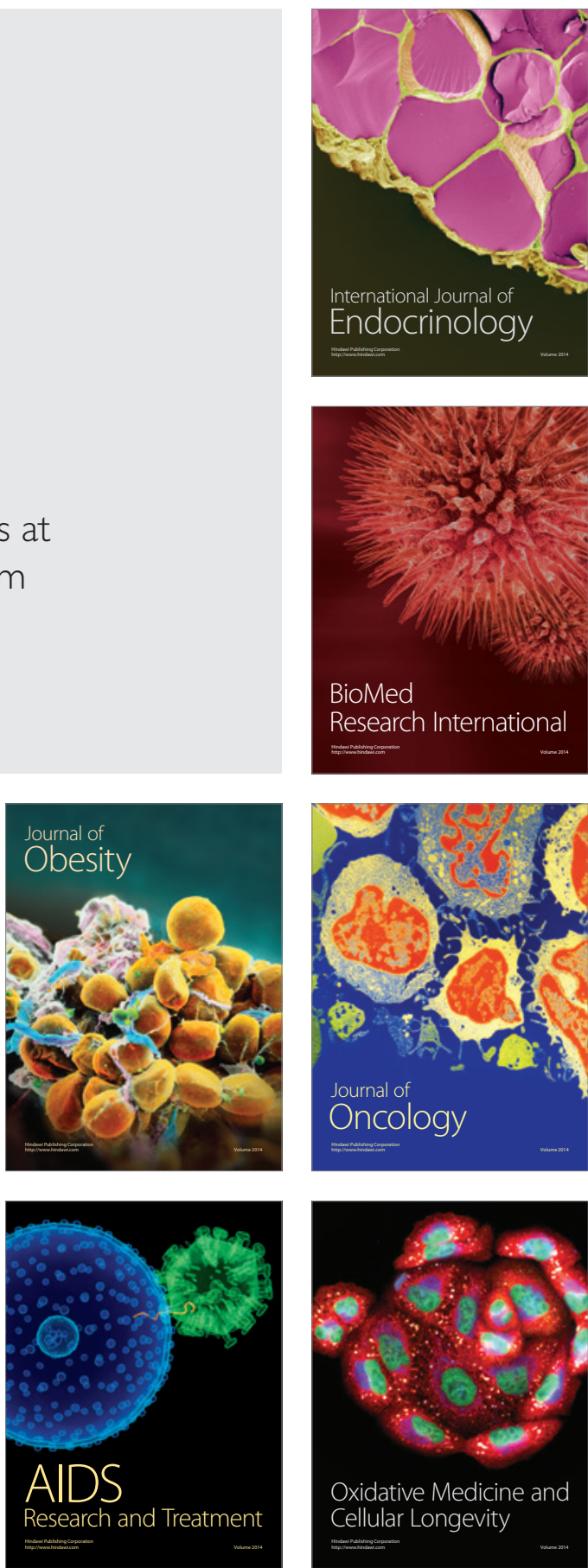